\title{
Green Aspects in Molecularly Imprinted Polymers by Biomass Waste Utilization
}

\author{
Roberta Del Sole*(D), Giuseppe Mele (D), Ermelinda Bloise and Lucia Mergola
}

Citation: Del Sole, R.; Mele, G.; Bloise, E.; Mergola, L. Green Aspects in Molecularly Imprinted Polymers by Biomass Waste Utilization. Polymers 2021, 13, 2430. https:// doi.org/10.3390/polym13152430

Academic Editors:

Nicolas Sbirrazzuoli, Andreia F. Sousa and Nathanael Guigo

Received: 21 June 2021

Accepted: 21 July 2021

Published: 23 July 2021

Publisher's Note: MDPI stays neutra with regard to jurisdictional claims in published maps and institutional affiliations.

Copyright: (c) 2021 by the authors. Licensee MDPI, Basel, Switzerland. This article is an open access article distributed under the terms and conditions of the Creative Commons Attribution (CC BY) license (https:/ / creativecommons.org/licenses/by/ $4.0 /)$.
Department of Engineering for Innovation, University of Salento, via per Monteroni Km1, 73100 Lecce, Italy; giuseppe.mele@unisalento.it (G.M.); ermelinda.bloise@unisalento.it (E.B.); lucia.mergola@unisalento.it (L.M.)

* Correspondence: roberta.delsole@unisalento.it

\begin{abstract}
Molecular Imprinting Polymer (MIP) technology is a technique to design artificial receptors with a predetermined selectivity and specificity for a given analyte, which can be used as ideal materials in various application fields. In the last decades, MIP technology has gained much attention from the scientific world as summarized in several reviews with this topic. Furthermore, green synthesis in chemistry is nowadays one of the essential aspects to be taken into consideration in the development of novel products. In accordance with this feature, the MIP community more recently devoted considerable research and development efforts on eco-friendly processes. Among other materials, biomass waste, which is a big environmental problem because most of it is discarded, can represent a potential sustainable alternative source in green synthesis, which can be addressed to the production of high-value carbon-based materials with different applications. This review aims to focus and explore in detail the recent progress in the use of biomass waste for imprinted polymers preparation. Specifically, different types of biomass waste in MIP preparation will be exploited: chitosan, cellulose, activated carbon, carbon dots, cyclodextrins, and waste extracts, describing the approaches used in the synthesis of MIPs combined with biomass waste derivatives.
\end{abstract}

Keywords: biomass waste; molecularly imprinted polymers; ion imprinted polymers; chitosan; cellulose; cyclodextrin; carbon dots; activated carbon; magnetic polymers; surface imprinting

\section{Introduction}

\subsection{The Value of Biomass Waste}

The aim of green chemistry can be briefly described with a working definition in the following sentence: green chemistry efficiently utilizes (preferably renewable) raw materials, eliminates waste, and avoids the use of toxic and/or hazardous reagents and solvents in the manufacture and application of chemical products. Nowadays, its concepts are accepted in academic and industrial spheres on a worldwide basis, recognizing that the implementation of green chemistry strategies is beneficial both to lead to a cleaner and more sustainable world but that it is also economically advantageous with many positive social effects [1-5].

One of the aspects of green and sustainable chemistry that will be analyzed in this review is the valorization of biomass waste [6-12]. Currently, the amount of biomass waste generated from different sources has been dramatically increased.

In the light of these considerations, one of the main objectives is to drastically reduce the environmental impact of waste with the scope to promote the concept for their recycling and transforming it into value added products.

Generally, biomass waste has been addressed for power generation purposes and the production of valuable carbon-based compounds; however, it is important to remark that, in some cases, waste biomass-assisted synthesis is a less costly, more environmentally friendly, and renewable strategy, and therefore wastes may become ideal renewable resources for production of functionally engineered macro or nanomaterials. 
Numerous physical, chemical, and biological routes have been investigated to optimize the utilization of biomass waste with a special attention for green and sustainable techniques.

Biomass waste is an environmentally friendly renewable resource that can be obtained from agricultural residues, human activity waste, fishery, wood industry, livestock waste, and so on. Biomass waste is a widespread natural carbon source which mainly contains cellulose, hemicellulose, lignin, chitin, ash, and proteins, and thus it is particularly suitable to be used as precursor to prepare high valued carbon-based materials stimulating a sustainable approach. Recently, carbon materials obtained from biomass waste have shown potential applications in hydrogen storage, biomedicine, sorption materials, and so on. However even if biomass waste has a high carbon amount, for instance, plant biomass waste has values of cellulose of $30-60 \%$, hemicellulose of $20-40 \%$, and lignin of $15-25 \%$, only a small amount of biomass waste is utilized now, while most of it is discarded $[13,14]$.

\subsection{Fundaments of MIPS}

At present, green chemistry principles are fundamental in many scientific fields with an enhanced emphasis in chemical processes, and MIPs cannot be excluded from this focus.

Molecularly imprinted polymers (MIPs) are based on the formation of specific interactions between a template (atom, ion, molecule, complex or a molecular, ionic, or macromolecular assembly, including microorganisms) and a functional monomer and the successive polymerization in the presence of a large excess of a crosslinking agent. Then, the template is removed from the crosslinked polymer leaving into the polymeric network specific recognition sites complementary in shape, size, and chemical functionality to the template molecule. Thus, the resultant polymer can bind specifically the template molecules. The main advantages of MIPs are their high selectivity and affinity for the target molecule used in the imprinting procedure similarly to the well-known lock and key model used in biological processes. Imprinted polymers, compared to biological systems such as proteins and nucleic acids, have higher physical robustness, strength, and resistance to elevated temperatures and pressures and inertness towards acids, bases, metal ions, and organic solvents. In addition, their production is less expensive with a very high storage life, keeping their recognition capacity also for several years at room temperature [15-18]. MIPs' advantageous features permitted an extensive application in analytical field such as foods, drugs, biological, and environmental sectors for the detection, preconcentration or separation of several analytes [19-22]. Other MIPs applications such as drug delivery [23] and catalysis [24-26], tissue engineering [27] have be also considered. It is worth noting that several different MIPs formats have been developed such as bulk or monoliths, microspheres and core-shell materials, magnetically susceptible and stir-bar imprinted materials which are applicable as sorbents of solid-phase extraction. MIP sorbents can determine target analytes and ions in a very complex environment such as blood, urine, soil, or food, and they have gained interest in trace analysis of pollutants in environmental samples. On the other side, MIPs in the sensor field have seen electrochemical sensing as the preferred analytical technique, followed by optical detection with high improvements in sensitivity as well as a shift in research and development toward real-life applications and point-of-care testing in real human samples. Moreover, the research in MIP sensor devices is nowadays moving from laboratory research to large-scale manufacturing [22].

In the last twenty years, the number of articles and reviews on the topic of MIPs has continued to increase, as can be seen from a research on Scopus platform (Figure 1), which confirms the large interest of the scientific community towards this area that allowed continuous advances in design, preparation, characterization, and application of MIPs. 


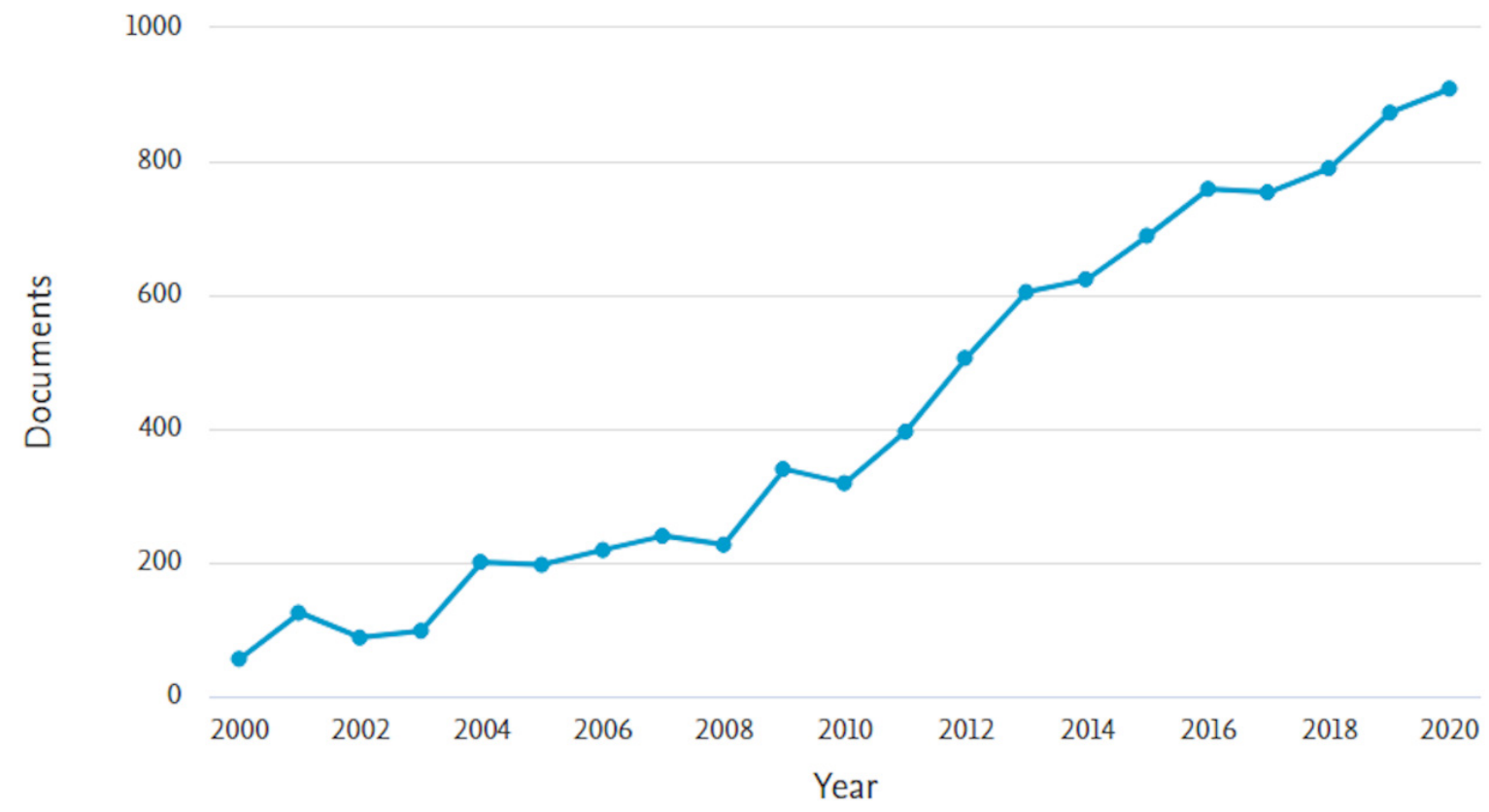

Figure 1. Number of papers per year with topic of molecularly imprinted polymers (Scopus platform, from 2000 to 2020 ).

Remarkable results have been achieved in the molecular imprinting field making it a mature technology even if there are significant findings and opportunities still open. Some work on MIPs takes into consideration green concepts, while others apply green principles without point out them. For instance, MIPs have a very promising future with great potential development in the food industry, theranostics and pharmaceutics but their applications in these fields, where toxicity specially needs to be contained, require more efforts to engage green approach to produce "green" MIPs. In the last decade, several high-quality reviews have been written on molecular imprinting [15-18], but most of them have dealt with the fundamental aspects and characteristic applications of MIPs while few review articles on novel techniques related to their preparation. Recently, only a few reviews highlighting the green aspect in MIPs preparation have been published $[20,28-31]$. On the other hand, to the best of our knowledge, there are no reviews focused on the transformation of biomass waste to produce natural substrates that can be used in place of other toxic substances generally employed for MIPs design.

Herein, we will explore the recent findings in the use of biomass wastes, such as natural polymers, as backbone-based materials to prepare green and biodegradable MIPs. This review aims to provide an overview on the value of using biomass waste as a key element in MIP preparation describing the different possible approaches in MIPs synthesis. In particular, several high value biomass waste derivatives will be considered in combination with MIPs.

The aim of this review is to give to the reader an overview of recent works that have seen the use of biomass in the preparation of MIPs. The next paragraph has been divided into six subparagraphs each of them dealing with a specific biomass waste. In detail, the following wastes will be taken into consideration: chitosan, cellulose, activated carbon, carbon dots, cyclodextrins, and waste extracts. The herein paper is not a critical collection of results of the above-cited topics but a comprehensive and useful summary of the state-of-art as starting point for future development in the topic of biomass waste for MIPs preparation.

\section{Different Biomass Waste in MIP Technology}

In the following subparagraphs, the added value of each different class of biomass waste in MIPs design will be highlighted. Their properties and preparation methods and some relevant examples on their utilization in MIP field will be shown. 


\subsection{Chitosan}

It is well known that Chitosan (CS) is the second most abundant natural biopolymer after cellulose which can be easily obtained from chitin, a widespread fish biomass waste. Chitin is the main structural component in the exoskeleton of various marine invertebrates. The natural polysaccharide CS has been attracting great attention in the scientific world, in fact the research of the descriptor "chitosan" on Scopus platform showed a regular exponential increase of papers in the last 30 years that has moved from only 120 papers in 1991 to 8183 papers in 2020 . The big interest on chitosan material can be justified from two points of view. First, CS satisfies various requests of green chemistry thanks to its abundance, nontoxicity, biodegradability, and biocompatibility. Moreover, from the second point of view, it has interesting physicochemical and biological properties such as water compatibility, the presence of chemical functional groups such as free amino and hydroxyl groups along its backbone capable of making interaction with metal ions and organic molecules or capable of making chemical reactions such as crosslinking or grafting processes, but also antimicrobial and antibacterial activities. Thus, CS has found successful utilization in several fields ranging from biomedical application (drug delivery, tissue regeneration, and wound healing), to wastewater treatment (adsorbent and sensors) till food, agriculture, cosmetics, papermaking, and textile applications. For instance, note that in the field of metal ion recovery technology, high importance is devoted in the use of green adsorption approaches such as the use of bioderived materials and chitosan-based adsorbents that represent an ideal example since the amine and hydroxyl groups of the CS chain can react with metal ions through chelation or ion-exchange mechanisms [32-36].

Chitin is a linear polysaccharide, made up of $(1,4)$-linked $N$-acetyl-D-glucosamine units, which is not used as is, but it is often converted into chitosan. Chitosan is produced by the alkaline partial deacetylation of chitin through enzymatic or chemical processes. The degree of deacetylation (DD), which determines the amount of free amino groups into the biopolymer chain, and it is responsible of its solubility and acid-base behavior, allows also to distinguish between chitin and chitosan: when DD values are lower than $60 \%$ the polymer is named chitin while for a DD value higher than $60 \%$ the polymer is named chitosan [37,38].

Chitosan mainly consists of $\beta(1-4)$-2amino-2-deoxy-D-glucose units with three types of free functional groups in the backbone: one amine group and two primary and secondary hydroxyl groups. Thus, CS structure can undergo numerous chemical reactions such as the reaction with aldehydes and acetones, hydrogen bonds, crosslinking, grafting, etc. When CS is dissolved in an acidic solution, amine groups protonate, and the polymer becomes positively charged and can interact with anionic molecules. CS behavior can be affected by several parameters such as $\mathrm{pH}$ and humidity. CS solubility in an acidic water environment allows to obtain CS in various forms, such as films, nanofibers, hydrogels, beads, membranes, or pastes. On the other hand, in some applications, such as the removal and separation of metal ions or organic pollutants from water solutions, adsorbents should have insolubility in water and also good mechanical strength in acid or alkali solutions. Thus, treatments of chitosan with crosslinking agents or by grafting are common strategies to improve its mechanical stability and insolubility.

The functional properties of CS can be also improved when combined with other materials. Therefore, starting from the natural capability of chelating metal ions and from the numerous excellent properties described above, chitosan is nowadays considered an optimal functional monomer for ion imprinted polymers (IIPs) or molecularly imprinted polymers making it a promising alternative to other functional monomers. In the last decades, many researchers have synthesized several chitosan-based IIPs using chitosan as functional monomer or supporting matrix $[37,38]$.

The first paper with a clear application of CS in IIP technology dates to 2001. Tianwei at al. demonstrated that a Ni(II)-imprinted chitosan resin, obtained by crosslinking with epichlorohydrin and ethylene glycol diglycidyl ether, had a good chemical and physical stability and could be used many times without losing adsorption capacity, considerably 
enhancing the adsorption capacity and the selectivity toward metal ions [39]. From then to now, tremendous progress has been made as it has been summarized in some interesting reviews with this focus [40-42]. Xu et al. [40] wrote a review on the use of chitosan in MIPs in which described the commonly used crosslinkers agents, highlighting the crosslinking mechanisms. In 2020, two other reviews appeared dealing with CS-based MIPs with the aims to provide an overview of the value to use chitosan as a functional monomer with a focus on its applications in electrochemical sensors [41], while Karrat et al. presented a brief overview of the recent applications of MIPs and IIPs composites based on chitosan with the focus on separation and sensing applications [42].

CS has been used primarily as functional monomer or support material to obtain IIPs or MIPs for the recognition of many metal ions, such as heavy metal for environmental application, rare earths, and precious metals, but also for the recognition of organic molecules, such as organic pollutants, protein, and chiral compounds. They were achieved in a multitude of forms ranging from membranes, beads, resins, fibers, core-shell structures, foams to xerogels.

Even if chitosan satisfies green principles because it is a widespread and cheap fish biomass waste, the green principles are not always applied in the whole process that use chitosan. Thus, in a more comprehensive green perspective, it is desirable that researchers keep in mind and evaluate the green principles of all the design steps.

In the design of eco-friendly chitosan-based IIPs or MIPs nontoxic crosslinkers, nontoxic initiators and nontoxic solvents have been considered thus extending the application of MIP in pharmaceutical and food fields too. Herein only some recent works will be described, choosing some sophisticated design, in which different forms or types of CS-based MIPs or IIPs composites have been realized with the aim to show the great flexibility in the utilization of CS in MIPs field.

In many studies CS was used as imprinting functional polymer that, via crosslinking reactions in presence of the template, creates the imprinting effect and enhances insolubility and mechanical strength. Various crosslinker agents have been used such as glutaraldehyde [43,44] epichlorohydrin [45,46], sulfuric acid, glyoxal [47], and so on.

Moreover, recently an increasing number of examples of MIPs or IIPs combined systems, in which chitosan has been combined with other materials, mainly nanomaterials, has been observed. In these contexts, we can cite the use of magnetic nanoparticles, graphene, multiwalled carbon nanotubes (MWCNTs), gold nanoparticles (AuNPs) capable of adding other optimal properties such as magnetic, electrical or high surface area [42].

Bagheri et al. [48,49] realized two different core-shell CS-based magnetic MIPs combining the utilization of a green synthesis strategy and the versatile magnetic solid-phase extraction (MSPE) technique, with the advantage of an external magnet that avoids filtration, centrifuge and precipitation procedures. $\mathrm{Fe}_{3} \mathrm{O}_{4}$ nanoparticles were used as core and CS as shell. In his first work [48], a dummy MIP was prepared in aqueous solution and used as sorbents of MSPE for an efficient clean-up and pre-concentration acrylamide (AA) in biscuit samples. First, $\mathrm{Fe}_{3} \mathrm{O}_{4}$ nanoparticles were synthesized by coprecipitation method. Nanoparticles were functionalized with PEG. Then, a layer of CS polymer was anchored onto $\mathrm{Fe}_{3} \mathrm{O}_{4}$ nanoparticles by surface imprinting in the presence of propanamide as dummy template. While in the last work [49], Bagheri et al. prepared a dual magnetic hydrophilic MIP used as sorbent for simultaneous pre-concentration and determination of valsartan and losartan from urine samples. $\mathrm{Fe}_{3} \mathrm{O}_{4}-\mathrm{COOH}$ nanoparticles were prepared with a co-precipitation method and then a layer of CS was crosslinked as MIP layer onto $\mathrm{Fe}_{3} \mathrm{O}_{4}-\mathrm{COOH}$ nanoparticles in the presence of valsartan and losartan target molecules (Figure 2).

Barati et al. [50] developed a selective sorbent for separation and preconcentration of fluoxetine in pharmaceutical formulation, human urine, and environmental water samples, by using a supporting material made of magnetic CS and graphene oxide through a coprecipitation process (Figure 3). CS was first mixed with iron magnetic nanoparticles and subsequently glutaraldehyde and graphene oxide were added to the mixture. After, 
the graphene oxide/magnetic chitosan nanocomposite was collected using an external magnet. MIP was synthesized on the surface of the supporting material by coprecipitation polymerization of methyl methacrylate and ethylene glycol dimethacrylate (EGDMA) in the presence of fluoxetine. The multi-imprinting sites and the large surface area of the magnetic chitosan/graphene oxide allowed a fast sorption and desorption kinetics and high sorption capacity, while the magnetic property of the supporting material allowed simple, rapid, and efficient separation of sorbent.

In another example of core-shell systems, Surya et al. developed chitosan gold nanoparticles, acting as core, decorated MIP (shell) which was used to modify the glassy carbon electrode (GCE) for the preparation of an electrochemical biomimetic sensor to detect the ciprofloxacin antibiotic [51]. The simultaneous presence of Au nanoparticles and CS-MIP allowed to enhance sensitivity and selectivity respectively, for the detection of the antibiotic. First, gold nanoparticles were prepared in the CS solution from reduction of gold chloride. Then, ciprofloxacin-imprinted polymer was prepared from polymerization of methacrylic acid (MAA), in the presence of the template after mixing with a dispersion of chitosan-based AuNPs. Finally, to prepare the sensor, the chitosan gold nanoparticles, decorated with MIP, were dropped cast onto the GCE surface and dried.

(a)

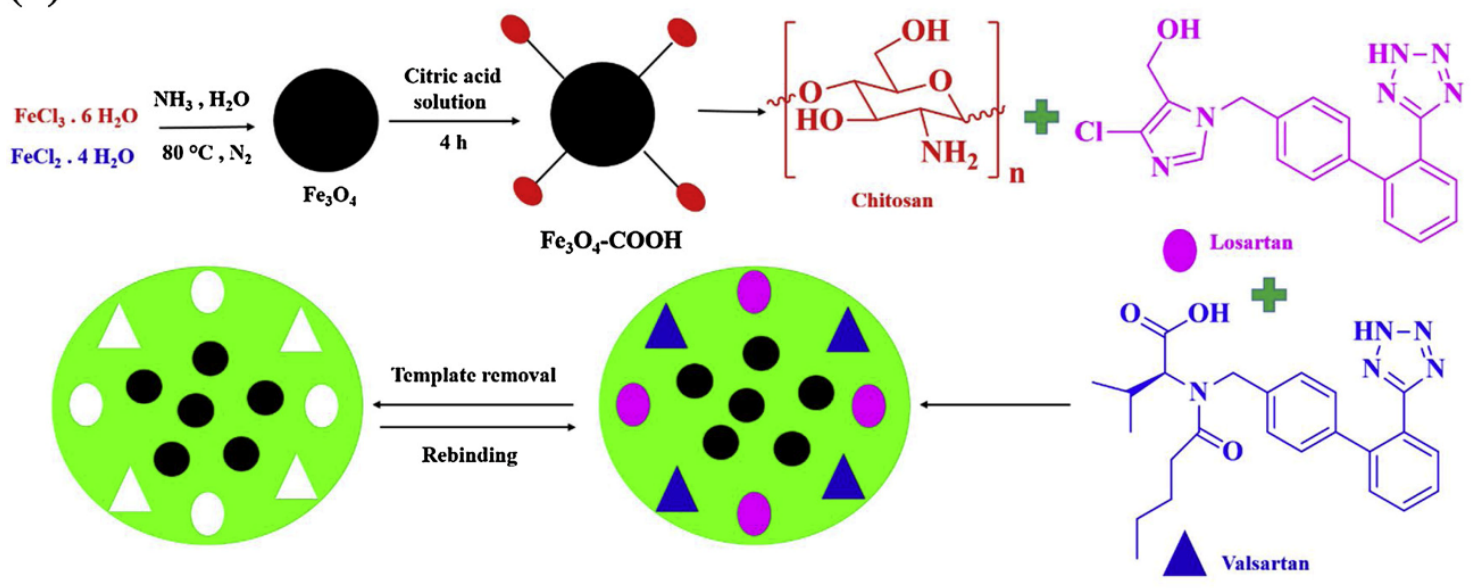

(b)
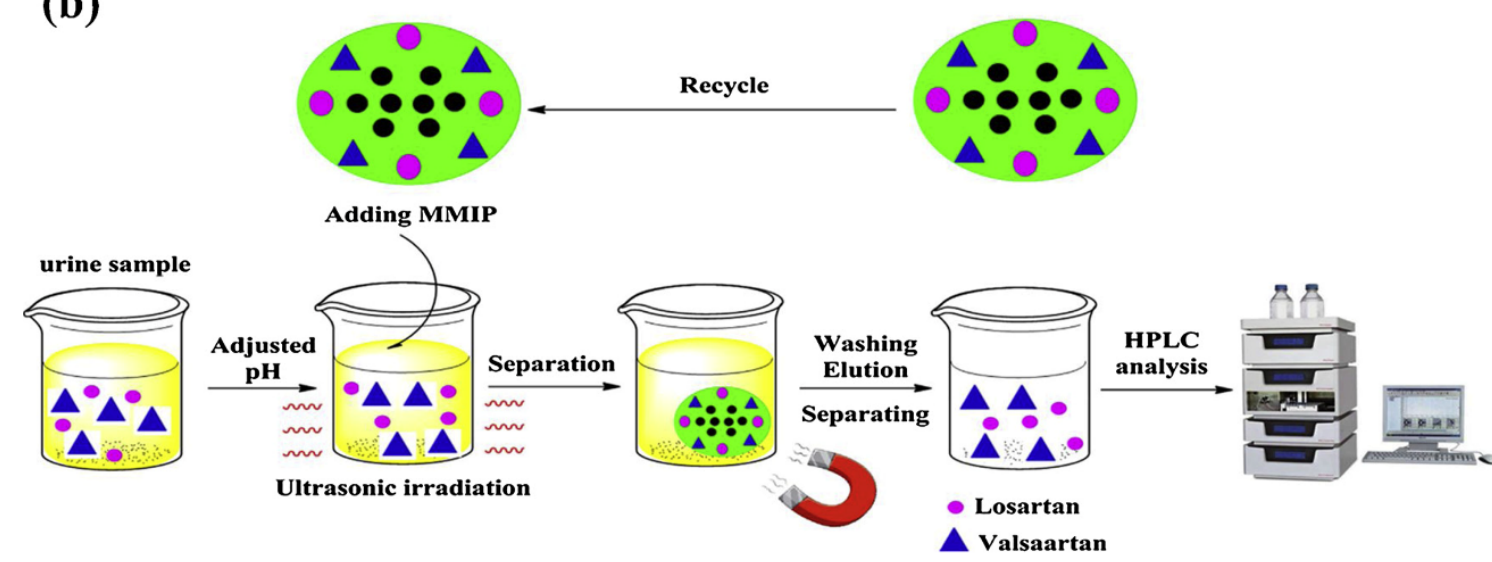

Figure 2. Synthesis procedure of magnetic MIP (a) and magnetic MIP for valsartan and losartan extraction (b). Reproduced from the work in [49] with permission from Elsevier. 


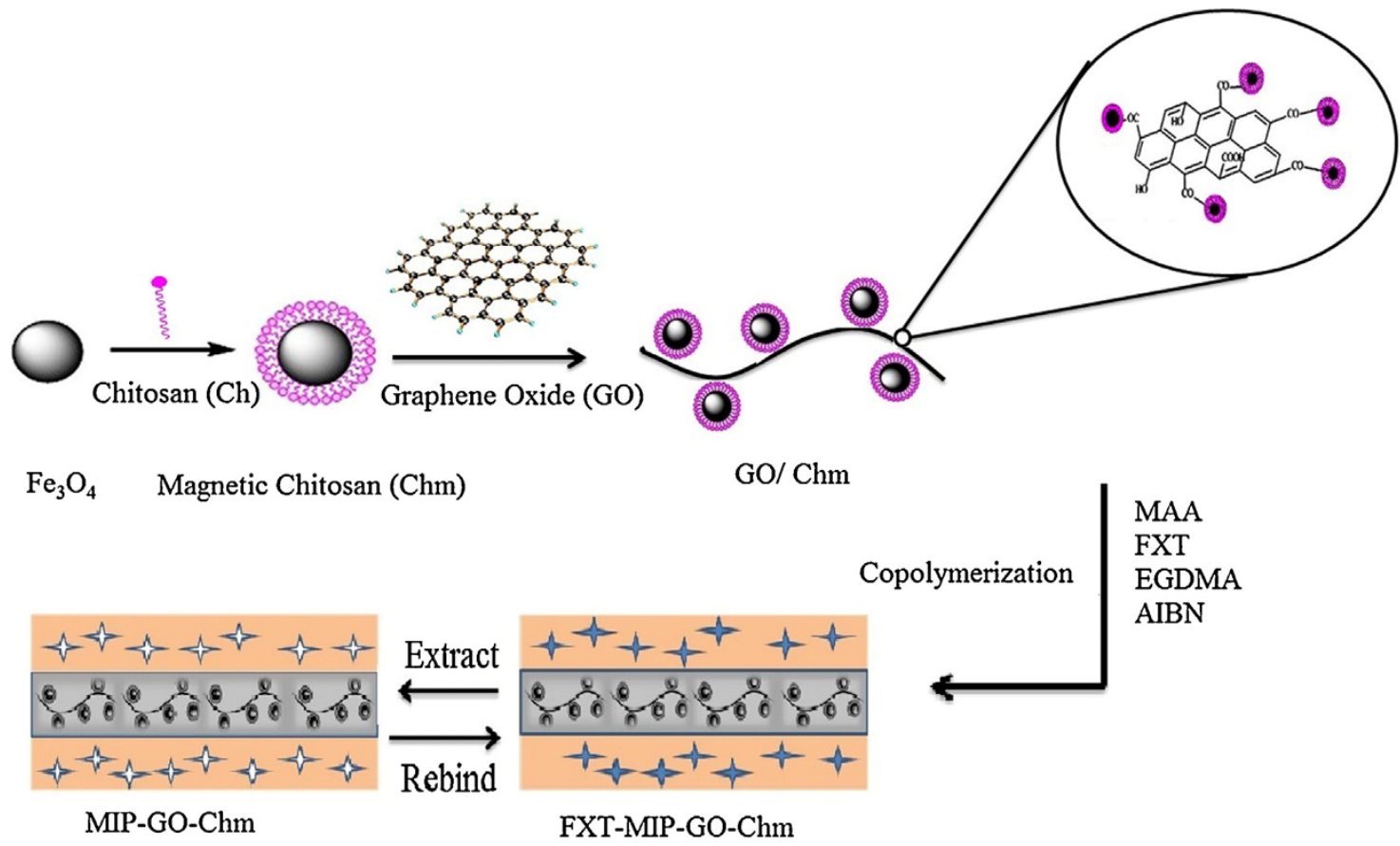

Figure 3. Preparation of magnetic chitosan/graphene oxide. Reproduced from the work in [50] with permission from Elsevier.

Recently, Wang et al. prepared green IIPs membranes in aqueous phase via the synergy of three eco-friendly and low-cost functional monomers: gelatin (G), 8-hydroxyquinoline (HQ), and CS. They were applied as effective and recyclable adsorbents to remove $\mathrm{Cu}(\mathrm{II})$ from aqueous solution (Figure 4). Various important factors able to affect adsorption capacity including $\mathrm{pH}$, temperature, and contact time, were investigated. Moreover, the fabrication of similar IIPs by using the same synthesis procedure but with other templates ( $\mathrm{Cd}(\mathrm{II}), \mathrm{Hg}(\mathrm{II}), \mathrm{Pb}(\mathrm{II}))$ allowed to demonstrate that the utilization of three functional monomers could be developed into a general imprinting strategy towards various heavy metal ions through multi-point interactions [52].
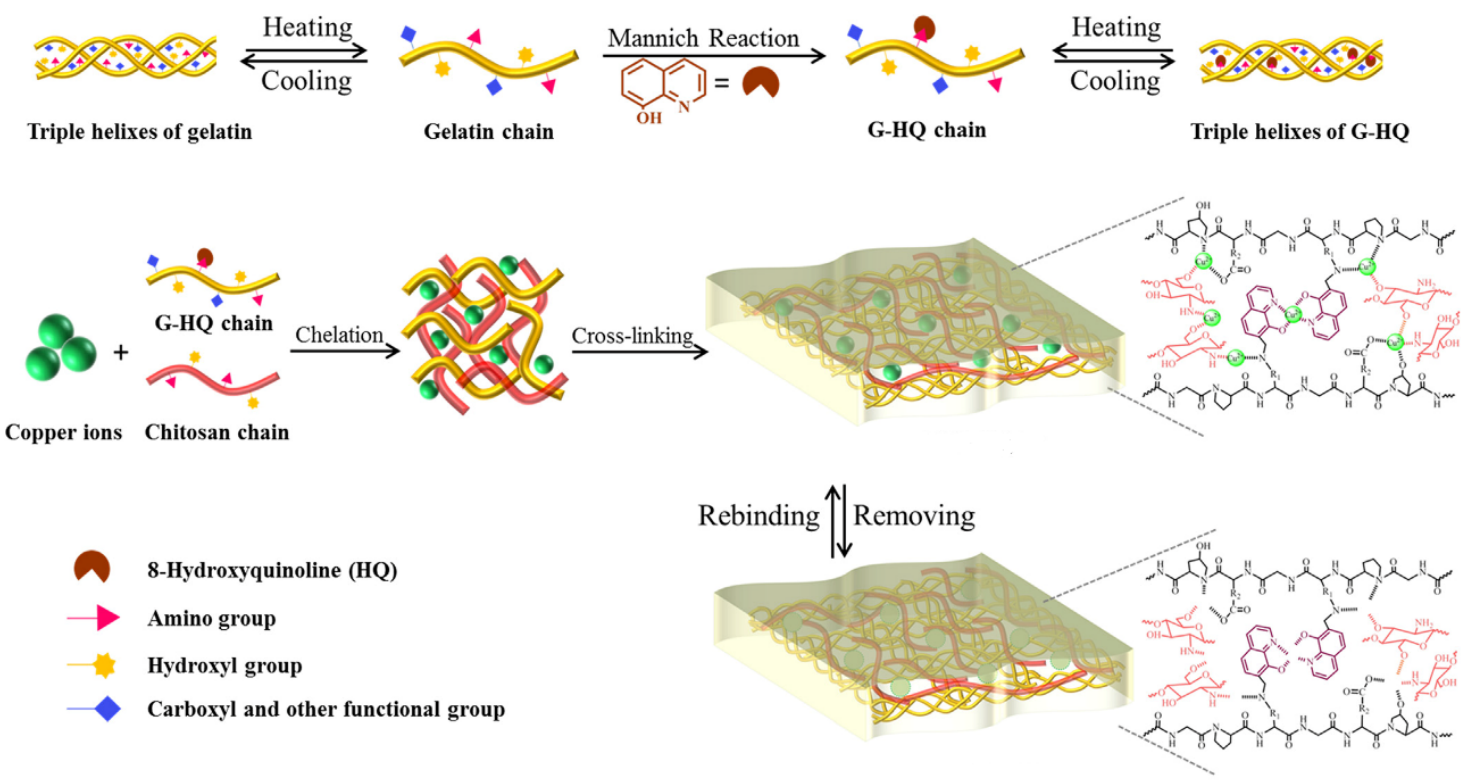

Figure 4. Description of preparation process for gelatin-8-hydroxyquinoline-chitosan (G-HQ-CS) ion imprinted polymers (IIPs). Reproduced from the work in [52] with permission from Elsevier. 
CS-based ion imprinted microspheres with high specific surface area were also prepared in microfluidic apparatus $[53,54]$. He at al. synthesized Ca(II)-CS microspheres for heavy metal ions removal from wastewater. The optimization of the preparation process allowed them to obtain uniform microspheres in size, morphology, and perhaps nature. The dispersed phase feed was an acidified aqueous solution containing chitosan and $\mathrm{Ca}(\mathrm{II})$. The continuous phase feed was an n-octane solution with Span 80 . The crosslinking bath was made up with n-octanol and $50 \mathrm{wt} \%$ glutaraldehyde aqueous solution and after phase separation of the mixture, the upper phase was out, and Span 80 was added as the crosslinking bath. The continuous phase and the dispersed phase were delivered into the microfluidic device, assembled with two thick plates and one thin plate in polytetrafluoroethylene, where the dispersed phase was introduced as small droplets. Crosslinking reaction with glutaraldehyde was conducted within the droplets collected in the crosslinking bath, as if the crosslinking agent entered the droplets by chemical potential driven interphase mass transfer (Figure 5).

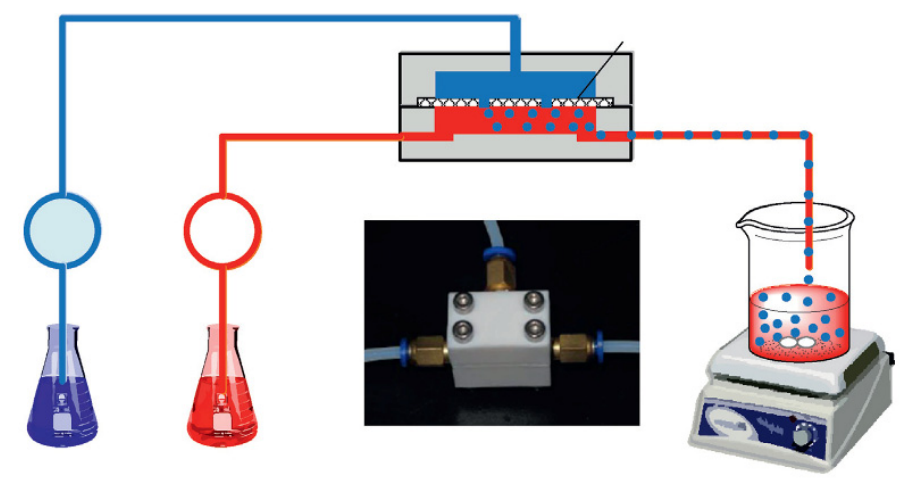

Figure 5. Description of $\mathrm{Ca}(\mathrm{II})-\mathrm{CS}$ microsphere preparation. Reproduced from the work in [53] with permission from Elsevier.

\subsection{Cellulose}

A biomass waste widely used in MIP preparation is cellulose, a very abundant polysaccharide in nature, synthesized by green plants, algae, and some bacteria species (Acetobacter xylinum, A. hansenii, A. pasteurianus, etc.). Cellulose consists of a linear chain of D-glucose units connected through B-1,4-glycosidic bonds and characterized from the presence of inter- and intramolecular hydrogen bonds that confer high stability to the structure. Crystalline and amorphous regions characterize its composition. However, different treatments [55-57] can remove the amorphous components, obtaining cellulose in crystalline form. Bacterial cellulose is different in composition from plant cellulose and possesses high purity and major crystallinity. The presence of methoxy and hydroxyl groups in cellulose monomers facilitates their functionalization and confers to the natural polymer high adsorption ability but also high hydrophilic characteristics [58].

Biodegradable and biocompatible characteristics but also the high resistance to acids, basics and common solvents and the high stability in water, make cellulose usable in a lot of application fields [59]. For many years, cellulose fibers were used for paper production, as an energy source and in textiles. Recently, cellulose has been employed in pharmaceutical application [60,61], drug delivery [62,63], as sorbent material in solid phase extraction and in MIP technology [58,64-67]. The growing interest of the scientific community towards the preparation of new advanced materials by green routes, prompted researchers to use cellulose as backbone-based materials to prepare green and biodegradable MIPs. In the last years, several papers on the usage of cellulose and cellulose derivatives as key element in the preparation of biodegradable and biocompatible MIP and IIP were published $[56,59,68-83]$. The prepared cellulose-based imprinted polymers were used in many application fields ranging from drug delivery, separation science, and also in 
environmental analysis of pollutants. A common cellulose modification adopted in many works is the addition of carboxylic residues on the cellulose backbone.

An interesting work conducted by Farenghi and co-workers, consists in the preparation of a water compatible cellulose-based MIP for Furosemide slow release in drug delivery studies [70]. First, microcrystalline cellulose was modified in sodium carboxymethyl cellulose (CMC) and used for the CMC-MIP design. In Figure 6, a synthetic route for CMC-MIP preparation was reported. After modification of microcrystalline cellulose, CMC was added in a preassembly solution containing the template (Furosemide) and the functional monomer acrylamide (AA). Then, CMC was crosslinked using 2-hydroxyethyl methacrylate as a co-monomer and ammonium peroxydisulfate as the CMC activating agent.

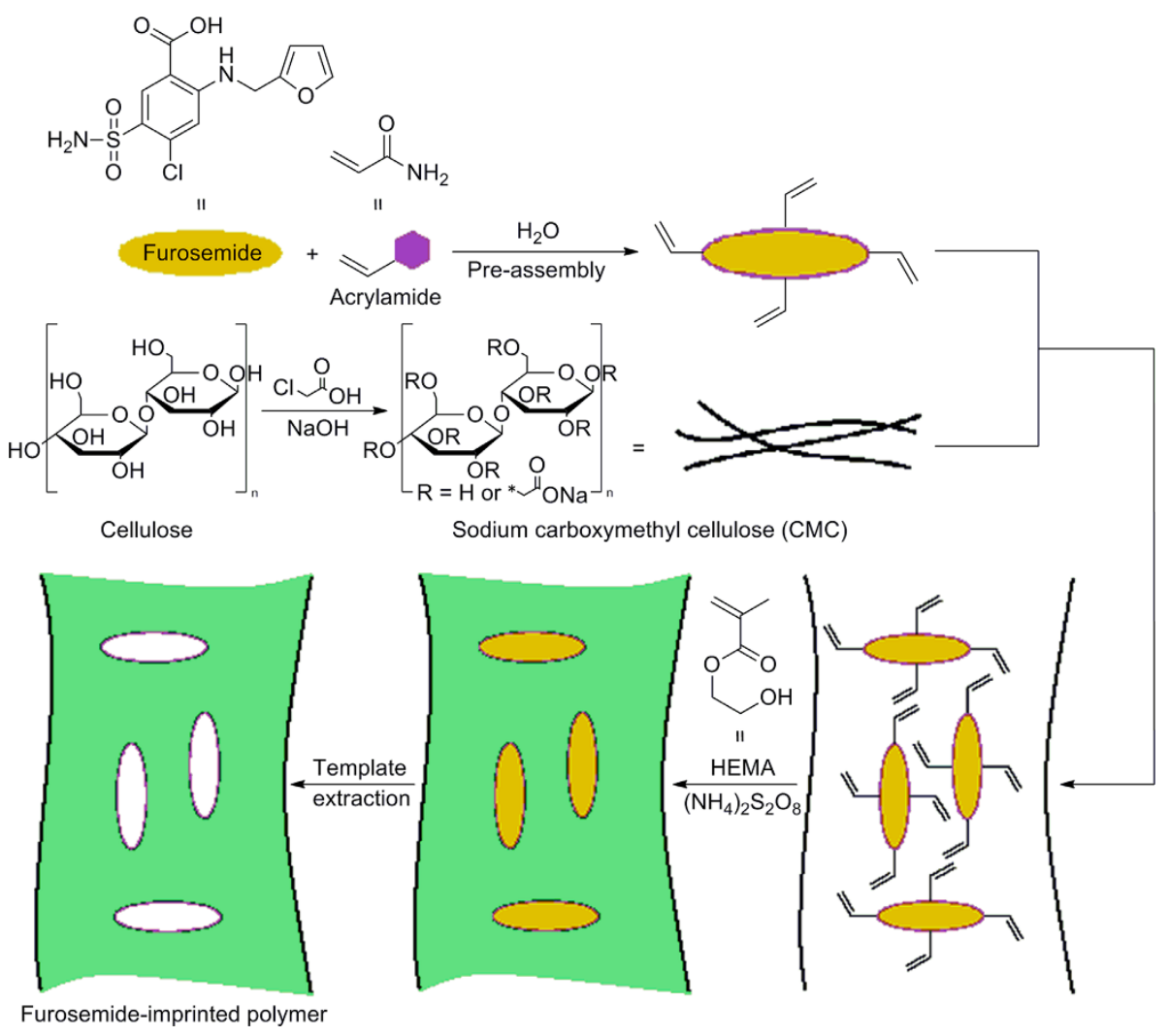

Figure 6. Synthesis procedure of cellulose-based MIP specific for Furosemide drug. Reproduced from the work in [70] with permission from Wiley.

In order to evaluate the binding performance of the polymer synthesized, binding studies were conducted revealing higher efficiency and selectivity of CMC-MIP compared with the corresponding non imprinted polymer (NIP). Finally, in vitro release studies, conducted in a phosphate buffer solution at $37^{\circ} \mathrm{C}$ in order to simulate arterial blood conditions, showed a higher loading capacity of CMC-MIP at the equilibrium state with a good control of the drug release rate compared to the corresponding CMC-NIP [70].

Carboxymethyl cellulose was also used as starting material for the preparation of a thiol-imprinted polymer for selective adsorption of $\mathrm{Hg}$ (II) [77]. In this case, CMC was crosslinked and stabilized with epichlorohydrin through an amide reaction. Then, carboxylic moieties of crosslinked CMC were modified by the thiol ligand Cysteamine in order to favor the complexation with $\mathrm{Hg}$ (II) ions. After the addition of the template ion, the functional monomer methylene bis acrylamide and ammonium peroxydisulfate as initiator, the reaction was conducted at $70^{\circ} \mathrm{C}$ for $12 \mathrm{~h}$. The adsorption ability of the polymer was tested, and a maximum adsorption capacity of $80 \mathrm{mg} \mathrm{g}^{-1}$ was obtained. Moreover, polymer efficiency was evaluated in real samples showing recoveries for $\mathrm{Hg}$ (II) of $86.78 \%$, $91.88 \%$, and $99.10 \%$ in wastewater, ground water, and tap water, respectively. 
Carboxylated cellulose nanocrystals, coupled with magnetic materials and combined with surface-imprinted polymer technique, were studied from $\mathrm{Hu}$ and co-workers to obtain a new adsorbent with high selective adsorption of fluoroquinolones in water [56].

Recently, Lin et al. [73] prepared for the first time a photo-responsive cellulose-based imprinted polymer (PR-Cell-MIP) as intelligent material for selective adsorption of typical pesticide residue, 2,4-dichlorophenoxyacetic acid. In this work, cellulose was first esterified to obtain a macromolecular initiator (Cell-ClAc). In order to confer photo-responsive characteristics, an Azo-containing functional monomer with carbon double band (Azo-CB) was synthesized and combined with the template in a pre-polymerization step. After, the photo-responsive cellulose-based imprinted adsorbent was synthesized via surfaceinitiated atom transfer radical polymerization (Figure 7). The results obtained showed remarkable adsorption performance $\left(\mathrm{Q}_{\max }=11.601 \mathrm{mg} \mathrm{L}^{-1}\right.$ with $89.03 \%$ of equilibrium template bindings), selectivity, stability, and reusability (8 cycles) of PR-Cell-MIP compared with the corresponding non imprinted polymer. Moreover, the presence of the Azo functional monomer, favors a green regeneration of the polymer through UV light.

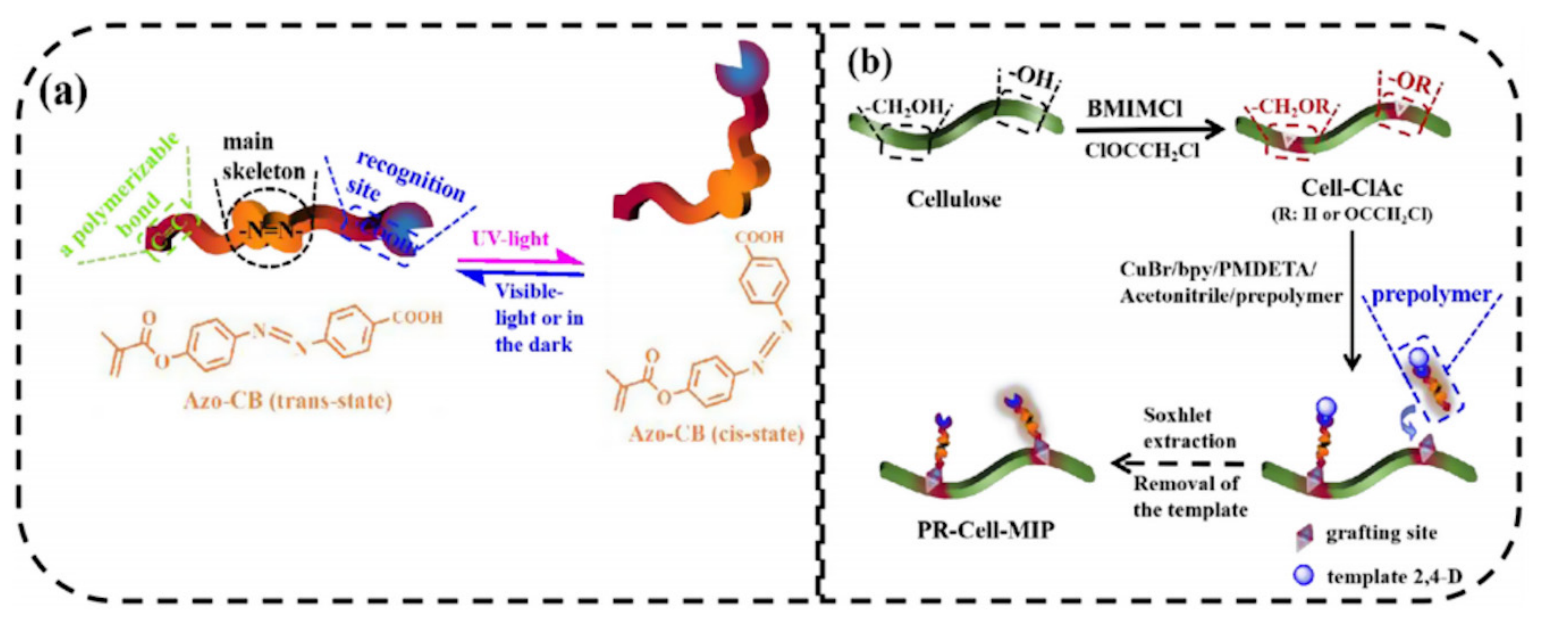

Figure 7. Schematic illustrations for (a) photo-responsive properties of the Azo-CB functional monomer and (b) synthesis route of PR-Cell-MIP. Reproduced from the work in [73] with permission from Elsevier.

Recently, many works have published in order to obtain efficient separation systems for heavy metals and rare earth element extraction. For this purpose, cellulose and their derivatives were widely used $[71,77,78,82-85]$.

An innovative methodology to prepare a new generation of IIPs for heavy metal ions extraction was introduced for the first time from Fattahi and co-workers [71]. Biological nanocrystal cellulose, obtained through acidic treatment of cotton wool, and cetyltrimethylammonium bromide were used as hard and soft templates respectively, in order to fabricate a new silica-based imprinted mesoporous polymers, via dual template method, for the simultaneous extraction of cadmium and lead ions from river water and fish muscles by micro solid phase extraction.

In a recent work, a stable and insoluble material was obtained using rice straw as support for cellulose-based lanthanum IIP preparation combining the imprinting technology with activators produced by electron transfer for atom transfer radical polymerization (AGET-ATRP) [85]. Hydroxyl groups present on the rice straw reacted with 2bromoisobutyryl bromide in presence of triethylamine in order to introduce the alkyl bromide initiator for surface-initiates AGET-ATRP. After, the polymerization was completed using the AGET-ATRP technique, with $\mathrm{Cu}(\mathrm{II}) N, N, N^{\prime}, N^{\prime}, N^{\prime \prime}$-pentamethyldiethylenetriamine $(\mathrm{Cu}(\mathrm{II}) / \mathrm{PMDETA})$ catalyst that was reduced in $\mathrm{Cu}(\mathrm{I}) / \mathrm{PMDETA}$ in the presence of ascorbic acid. The addition of functional monomer $N, N^{\prime}$-dimethylaminoethyl methacrylate (DMAEMA), crosslinking agent EGDMA, and template ion $\left(\mathrm{La}^{3+}\right)$ completes the preparation of the straw-supported imprinted polymer that was subjected to washing steps 
in order to remove the template ions from cavities present in the polymeric structure. The density of IIP polymer cross-linkage on the rice straw surface exerted great influence on the sorption property with a maximum sorption capacity of $125 \mathrm{mg} \mathrm{g}^{-1}$ obtained in several minutes.

In another work, Wu and co-worker prepared for the first time a three-dimensional macroporous wood-based selective separation membrane decorated with well-designed $\mathrm{Nd}$ (III)-imprinted domains in order to recover $\mathrm{Nd}$ ions [82]. First, a polydopamine (PDA)modified layer was synthesized on the basswood surface in order to obtain PDA-based basswood membrane (PDA@basswood) that was further modified through the addition of KH-570 to achieve polymerizable double bonds for the following two steps (Figure 8). Through a two-step temperature free radical polymerization process, obtained using $\mathrm{Nd}(\mathrm{II})$ ions as template, two functional monomers (MAA and AA) and EGDMA as crosslinking agent, a 3D-based ionic imprinted membranes (3DW-IIMs) system was obtained. Excellent results in terms of rebinding capacity $\left(120.87 \mathrm{mg} \mathrm{g}^{-1}\right)$; adsorption kinetics and permselectivity coefficients (more than 10) were obtained. Moreover, it was found the capability of the PDA-modified layer to enhance the rebinding performance of the 3DW-IIMs.

3D basswood structure PDA-based chemical structure Basswood-based

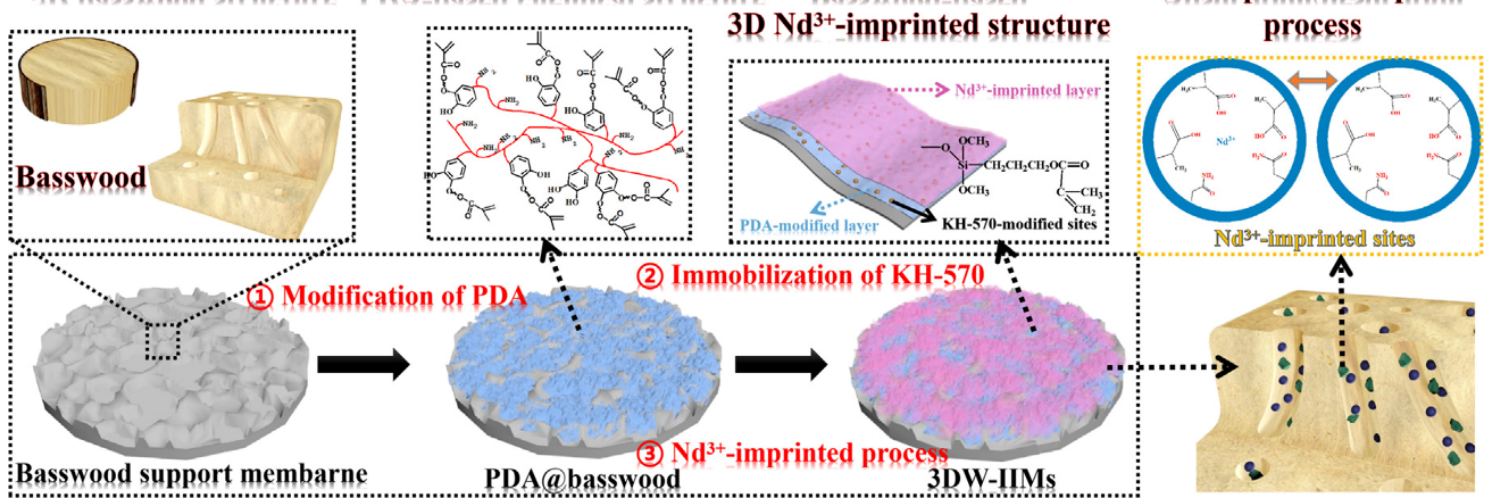

Figure 8. Synthesis route for 3DW-IIMs preparation. Reproduced from the work in [82] with permission from Elsevier.

\subsection{Activated Carbon}

Activated carbon is essentially a carbonaceous material with specific physicochemical properties, which make it attractive for different applications [12,86]. It is a black solid substance typically amorphous, microcrystalline, and non-graphite which cannot be identified with any determined chemical formula. Depending on its physical form, activated carbon can be characterized as powder, granule, extract, pellet, fiber, cloth, and so on. Its chemical structure has heteroatoms like oxygen, hydrogen, sulfur, and halogen as atoms or as functional groups chemically bonded into the structure. Among them, oxygen is the most common one and it is mainly included in carboxyl, phenol, carbonyl, and lactone functional groups into the inner or external surface of the material. The quality, the properties, and the characteristics of the chemical structure and surface chemical groups of the activated carbon depend on the precursor source and the oxidative activation treatment. Common physicochemical properties of activated carbon are high porosity, surface area and degree of surface reactivity together with high mechanical strength and physicochemical stability. Thanks to these properties, activated carbon has been extensively used for different applications where for example high adsorption capacity, hardness, or abrasion resistance are needed.

Precursor source or starting material of activated carbon can be either natural or synthetic carbonaceous solid one. The most common sources on the market are petroleum residues, wood, coal, peat, and lignite. Most of them are expensive and not renewable. Recently, other precursors have been taken into consideration, and many research works have been focusing on the activated carbon production starting from agricultural waste and 
lignocellulose materials. Even if carbon content in these previously mentioned precursors is lower than the carbon content in coal, anthracite, or peat, biomass waste is very attractive because of its relatively low cost, its green aspects (as the waste could be converted into capital), and it can be considered renewable and capable to solve environmental concern. Several biomass sources have been used to produce activated carbon such as coconut shell, sugarcane bagasse, coffee ground, hazelnut shell, olive waste cake, rice husk, groundnut shell, hazelnut bagasse, kenaf fiber, or coconut husk [86-88].

Activated carbon preparation from biomass waste can be realized through a physical or a chemical treatment. Physical treatment is carried out in two steps: firstly, the carbonization occurs by a thermal process, heating in a range of 400 to $850{ }^{\circ} \mathrm{C}$ and successively the activation process is made by using steam or carbon dioxide at a temperature of $600-900{ }^{\circ} \mathrm{C}$. By contrast, in chemical treatment only a step is needed: an activating agent is added to the biomass waste in order to allow starting material dissolution and crosslinking formation, and a thermal process under inert atmosphere is made.

Activated carbon has been applied in several fields as supported from the huge literature published in the last decades such as water treatments, chemical and pharmaceutical industries, catalysis, energy storage, batteries, nuclear power stations, and supercapacitors [87-90].

Recently, some papers focusing on the use of activated carbon in molecular imprinting technology have been also published [91-94]. In fact, advantages of typical activated carbon properties especially high porosity, high surface area, and the presence of functional groups (carboxyl, carbonyl, or phenol) on its surface as well as environmentally friendly are combined with selectivity typical of molecular ion imprinting technology.

It is well known that activated carbon are excellent adsorbents for many heavy metal ions and organic pollutants even if they are often unable to distinguish between different metal ions or organic pollutants. In this contest, Zhang et al. in a recent work improved the selective adsorption capacity of activated carbon, called biochar, by using ion imprinting technology [91]. The authors used biochar, prepared by processing agricultural waste under slow pyrolysis at $600^{\circ} \mathrm{C}$ for $10 \mathrm{~h}$, as the substrate material to obtain an ion-imprinted functionalized sorbent for $\mathrm{Cd}(\mathrm{II})$ from wastewater. Biochar was first activated with hydrochloric acid and then it was modified using 3-mercaptopropyltrimethoxysilane as the surface conditioning agent and epoxy-chloropropane as the crosslinking agent, in the presence of a hydrate chloride salt of cadmium(II) in ethanol in order to prepare the ion-imprinted sorbent (IB). The obtained results demonstrated the higher selectivity for $\mathrm{Cd}(\mathrm{II})$ of the imprinted biochar (IB) even in the presence of $\mathrm{Co}(\mathrm{II}), \mathrm{Pb}(\mathrm{II}), \mathrm{Zn}(\mathrm{II})$, and $\mathrm{Cu}(\mathrm{II})$ interferences.

Glycoproteins are crucial in many biological events, such as protein folding and nerve conduction, and some glycoproteins can be used as disease biomarkers. However, selective detection of glycoproteins at trace level in complex biological matrices remains an urgent issue. To address this, in a very recent work, Ding et al. developed a very interesting biomass activated carbon-derived imprinted polymer (BAC@PEI/PBA/MIPs) for selective recognition of glycoprotein [94]. They combined biomass active carbon with surface imprinting technique to obtain a biowaste-derived imprinted polymer for specific albumin recognition through an easy synthetic strategy starting from low-cost materials. The BAC@PEI/PBA/MIPs was synthesized using waste tea derived carbon as matrix, albumin chicken egg as template, and dopamine as functional monomer. In order to prepare activated carbon, dried waste tea was mixed with potassium ferrate and annealed at $800{ }^{\circ} \mathrm{C}$ for $1 \mathrm{~h}$ under nitrogen. Then, carboxylation was carried out with sodium nitrate and potassium permanganate in acidic environment. Moreover, the binding capacity was significantly increased thanks to the branched polyethyleneimine (PEI) which was covalently bonded on the activated carbon surface before to carry out the surface imprinting, in order to increase the number of boronic acid sites. After that, the boronic acid molecules were immobilized via amine aldehyde condensation reaction (Figure 9). As the molecular weight of PEI can affect the binding capacity, Ding et al. prepared different BAC@PEI/PBA/MIPs with PEI at various molecular weights and the binding 
capacity was evaluated. The binding performance of BAC@PEI/PBA/MIPs compared with some reported glycoprotein-MIPs was superior, with a faster mass transfer rate of the BAC@PEI/PBA/MIPs than the most reported MIPs, even if the imprinting factor need to be improved.
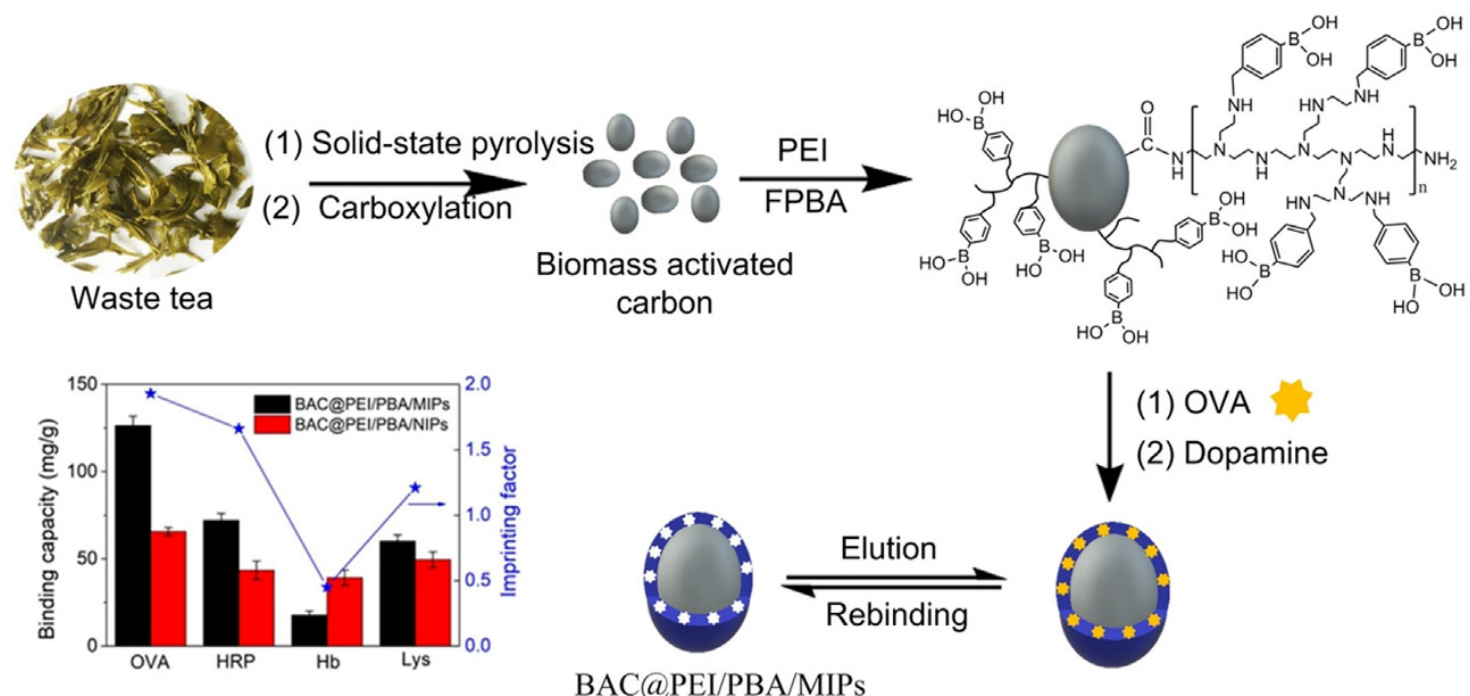

Figure 9. Synthesis procedure, binding capacity and imprinting factors of BAC-based molecularly imprinted polymers. Reproduced from the work in [94] with permission from Elsevier.

Taking into consideration the huge amount of carbon dioxide released in the atmosphere, it is vital to develop advanced carbon dioxide adsorption materials for protecting the environment. To this aim, carbon capture and storage represents a convenient environmentally friendly way for reducing atmospheric $\mathrm{CO}_{2}$. In this context, in another very recent work, $\mathrm{Su}$ et al. prepared a $\mathrm{CO}_{2}$-imprinted polymer on the surface of activated carbon for effective capture of $\mathrm{CO}_{2}$ from flue gas [92]. Sustainable carbon was derived from sunflower heads while the surface imprinting technique was used with ethanedioic acid and AA as template molecule and functional monomer, respectively. The authors optimized the imprinted polymer by changing the ratio of $\mathrm{KOH}$ to sunflower-based activated carbon, carbon dosage, and adsorption temperature. Adsorption, selectivity, and regeneration properties of the optimized imprinted polymer were evaluated. A maximum $\mathrm{CO}_{2}$ adsorption capacity of the adsorbent of $1.71 \mathrm{mmol} \mathrm{g}^{-1}$ was found. Selective adsorption performance in the presence of $\mathrm{H}_{2} \mathrm{O}$ as well as in simulated flue gas was demonstrated. Moreover, regeneration by $\mathrm{N}_{2}$ purge at $120{ }^{\circ} \mathrm{C}$ showed a $\mathrm{CO}_{2}$ adsorption capacity decreasing of $11 \%$ after five adsorption/desorption cycles.

Finally, it is interesting to describe the work of Saputra et al. [93]. The authors reviewed the synthesis of biosensors from teak lignocellulosic material. They describe a type of activated carbon preparation technique with intrinsic products such as the stable nature of chemical reaction, porous structural hierarchy, and decreased detection limits. Nanocarbon was obtained into a drum-kiln at $400-500{ }^{\circ} \mathrm{C}$ for $7-8 \mathrm{~h}$. Then, the activated carbon was produced at $800{ }^{\circ} \mathrm{C}$ for $1 \mathrm{~h}$ with $\mathrm{H}_{2} \mathrm{O}$ and potassium hydroxide activator. MIP and NIP synthesis techniques were applied for biosensor production for melamine detection, while potential measurements and detection limits were used to measure product performance. The results showed an optimal formula for a mixture of 15\% MIP, 45\% carbon, and 40\% paraffin which produced a Nernst factor of $49.7 \mathrm{mV}$ decade $^{-1}$ and detection limit of $1.02 \times 10^{-6} \mathrm{M}$.

\subsection{Carbon Dots}

Fluorescent carbon dots (CDs) are emerging quantum nanomaterials derived from carbon materials that have attracted significant attention compared to conventional semi- 
conductor quantum dots thanks to more interesting properties such as bright good stability, fluorescence, noticeable electrochemical activity, easy synthesis, proper surface functionalization, and especially non-toxic features $[13,95]$.

They appeared for the first time in 2004 in a work of Xu et al. [96], and they were named as carbon dots two years later by Sun et al. [97]. From their discovery until now, the scientific community has been devoting enormous consideration to CDs due to their excellent characteristics. They are well-dispersed fluorescent carbon nanospheres with particle size below $10 \mathrm{~nm}$. Several great properties are typical of CDs such as good biocompatibility, easy chemical surface modification, high chemical inertness, noticeable electrochemical activity, green and easy synthetic strategy, and good water solubility. Special attention should be given to their fluorescent characteristics which are also possessed by traditional semiconductor quantum dots, which make them good competitors: a broad absorption spectrum, multiple generations, high photostability, and fluorescent intensity, and their emission spectrum generally changes by changing excitation wavelengths or by changing nature of functional groups on the surface. Similar to quantum dots, the emission of carbon dots is related to their size. Thus, valuable CDs have been used as fluorescent probes for biological or environmental detection [95]. When CDs are included in a sensor system, the main challenge is to find the proper matrix which can preserve the photoluminescence activity and avoid leaking of carbon dots. CDs are also finding application in other fields such as cell imaging, in vivo imaging, drug delivery [98], photocatalysis [99], multicolor light-emitting diode production [100], and energy conversion and storage [101].

CDs properties such as morphology, fluorescence, and luminescence efficiency depend on the preparation method and on the nature of starting material. Development of synthetic strategies to get CDs with defined properties is still in progress since it is only at an early stage. There are two main synthetic pathways followed to produce CDs: top-down and bottom-up approach. The first one goes from larger carbon materials (activated carbon, graphite, carbon nanotube, large-size graphene, etc.) to carbon dots by using electrochemical oxidation, arc discharge or laser ablation technique. Some disadvantages of this method such as the use of strong experimental conditions, time consuming operation steps and high-cost equipment have limited its use. On the other hand, the bottom-up method converts small molecules into carbon dots through carbonization and passivation steps by using microwave-assisted, pyrolysis or solvothermal, ultrasonic-assisted methods. Some advantages typical of this method such as cost-effectiveness, easy operation and simple equipment requirements allowed an extensive employment of it.

Starting materials for CDs preparation are very widespread and even if organic or inorganic carbon sources are both available, due to some limits of the inorganic one, organic carbon sources represent the main font of carbon dots. Between the different organic carbon classes considered, biomass waste has been recently used as raw material for CDs synthesis for the reasons and advantages widely discussed in the current review. Numerous biomass wastes have been used for carbon dots preparation such as sugarcane bagasse char, waste food, orange or lemon peels, onion waste, coffee grounds, tea or rice residues, wheat bran or straw, bamboo leaves, coconut husks, lignite, and so on [13,102].

CDs are good candidates to be combined with molecular imprinting technology as specific recognition site, selectivity, and stability typical of MIPs enable them to enhance the unique optical and electronic properties of CDs. In fact, one of the main limits of CDs in sensor application is their lack of selectivity to the analyte as long as the presence of interferences in complex matrices responsible for quenching fluorescence emission spectrum of CDs. Thus, with the aim to enhance selectivity, sensitivity, and anti-interference ability, some attempts to apply CDs in the MIP field have been made in the last few years. Note that the relevance and success of the carbon dot-based MIP research area has been demonstrated from the publication of some reviews in 2020 with this specific topic where a description in deep several studies of CDs combined with MIP can be found [20,103,104], where optical/ fluorescence sensors represent the main explored application of CDs combined with MIP. In this context, even if Ansari et al. [20] dedicated a paragraph for CDs derived from 
biomass waste, they reported only two examples where CDs were synthesized from sweet potato peels and cedrus, respectively $[105,106]$. Thus, herein other relevant studies recently appeared in literature will be described highlighting some aspects of carbon dots synthesis from biomass waste. As it can be seen, CDs can be utilized as a support material for surface imprinted polymers to develop selective and sensitive sensors.

It can be observed that Liu adopted a green approach for CDs preparation starting from sweet potato peels [105] and longan peels [107] as carbon biomass waste source by using a hydrothermal synthesis, avoiding toxic solvents or complicated procedures. While in their previous work, Liu et al. developed a MIP-coated CDs by using a hydrothermal synthesis in water heating at $200{ }^{\circ} \mathrm{C}$ for $3 \mathrm{~h}$ in autoclave, in a successive paper published in 2020, Liu et al. used an easier method to obtain CDs from biomass waste, mixing longan peels and water and heating at $200^{\circ} \mathrm{C}$ inside a high-pressure microwave, which allowed to decrease preparation time at $30 \mathrm{~min}$. The carbon dots coupled with restricted access materials and molecularly imprinted polymers (CDs@RAM-MIPs) composites were prepared by using CDs, metronidazole, AA and EGDMA as fluorescent materials, template molecule, functional monomer, and crosslinker respectively. Moreover, glycidyl methacrylate was also used as co-polymerization functional monomer to produce a large amount of hydroxyl groups and to make the composites more hydrophilic. The results demonstrated that CDs@RAM-MIPs can be used as specific and selective probes for trace detection of metronidazole in serum samples.

Sun et al. fabricated a fluorescent probe based on MIPs combined with carbon quantum dots used for selective adsorption of mesotrione with fluorescence quenching to determine the analyte in corn. Carbon quantum dots were prepared through a hydrothermal method using mango peels as carbon source, and the whole synthesis procedure was green without chemical reagents. Then, CDs were encapsulated into MIPs by using sol-gel technology (Figure 10). The MIP probe was successfully applied to determine mesotrione in a complex matrix as a low detection limit of mesotrione of $4.7 \mathrm{ppb}$ and a high selectivity with an imprinting factor of 5.6 were found [108].

In a recent paper, Kazemifard et al. described the use of rosemary leaves, as a carbon source, to synthesize CDs [109]. Following the rules of green chemistry related to the elimination or minimization of the use or production of harmful chemicals, the authors used only water and rosemary leaves. The powder of dried leaves was added to water and heated at $180^{\circ} \mathrm{C}$ for $12 \mathrm{~h}$. Carbon dots were purified by centrifugation and filtration of the supernatant. Then, the surface of the CDs was chemically modified to obtain a crosslinker for MIP in order to prepare an optical probe for the determination of thiabendazole (TBZ) and it was successfully applied for the quantification of TBZ in apple, orange, and tomato juices. In detail, a silica shell using tetraethoxysilane (TEOS) was stabilized on the surface of CDs via reverse microemulsion technique. Following, MIPs were synthesized in the presence of TBZ as a template, using 3-aminopropyl triethoxysilane and TEOS as a functional monomer and a crosslinker, respectively.

In a work of Demir et al. [110], for the first time a core-shell CD-MIPs as a biocompatible optical imaging tool for targeted bioimaging of cancer cells, was described. Glucuronic acid was used as template by using the epitope approach for hyaluronan recognition, a biomarker for specific cancers. $N$-doped CDs were prepared by hydrothermal synthesis using starch as carbon source and L-tryptophan as nitrogen atom in water. The mixture was heated at $160{ }^{\circ} \mathrm{C}$ for $12 \mathrm{~h}$ and then centrifuged. The supernatant was filtered, and CDs were purified by using size-exclusion chromatography. Then, a thin shell of MIP was photopolymerized around the CDs surface by using CDs light emission as light source for photopolymerization. In this work, the biotargeting and bioimaging of hyaluronan on defined human cervical cancer cells, using CD core-MIP shell nanocomposites, was demonstrated. A brief overall description of the study is shown in Figure 11.

Finally, it is interesting to describe a work that shows the great potential of MIPs combined with carbon dots in the photocatalysis field. In most reports, CDs/semiconductor hybrid photocatalysts exhibit excellent optical properties and photogenerated carriers 
transfer characteristics [99]. Taking into account this CDs property, Yu et al. in 2021 provided a molecularly imprinted black $\mathrm{MIP}-\mathrm{TiO}_{2-\mathrm{x}} / \mathrm{CQDs}$ nanocomposite material to efficiently photodegrade target pollutants in wastewater. $\mathrm{CDs}$ were obtained from lignite dispersed in $\mathrm{H}_{2} \mathrm{O}_{2}$ and formic acid, stirred at $80^{\circ} \mathrm{C}$ for $3 \mathrm{~h}$. After a filtration, diethylenetriamine was added and heated at $180^{\circ} \mathrm{C}$ for $6 \mathrm{~h}$. The composites were prepared via a facile two-step hydrothermal calcination method by using methylene blue as template. The unique optoelectronic properties of carbon dots can be more effectively utilized by introducing it into black $\mathrm{MIP}_{-} \mathrm{TiO}_{2-x}$. The insertion of carbon dots into black $\mathrm{MIP}^{-\mathrm{TiO}_{2-x}}$ not only improved the optical absorption ability, but also promoted the formation of $\mathrm{Ti}^{3+}$ ions and oxygen vacancies in $\mathrm{MIP}_{-} \mathrm{TiO}_{2-x}$ nanocomposites and effectively enhanced the separation of photogenerated (Figure 12). In fact, the results showed an improvement of photocatalytic activity of $\mathrm{MIP}^{-\mathrm{TiO}_{2-x}} / \mathrm{CDs}$ to methylene blue under visible light [26].

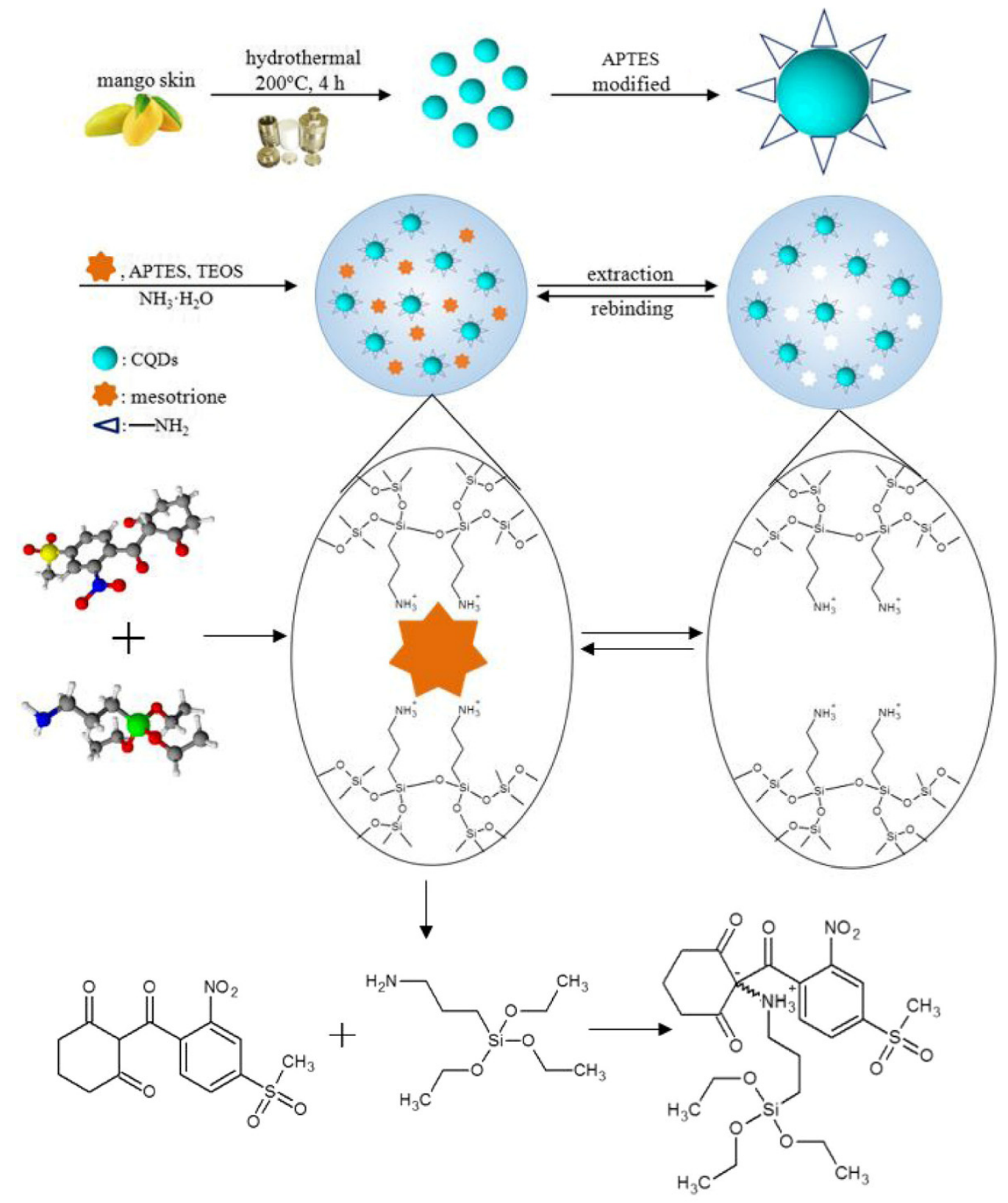

Figure 10. Synthesis preparation of CQDs@MIPs. Reproduced from the work in [108] with permission from Springer Nature. 


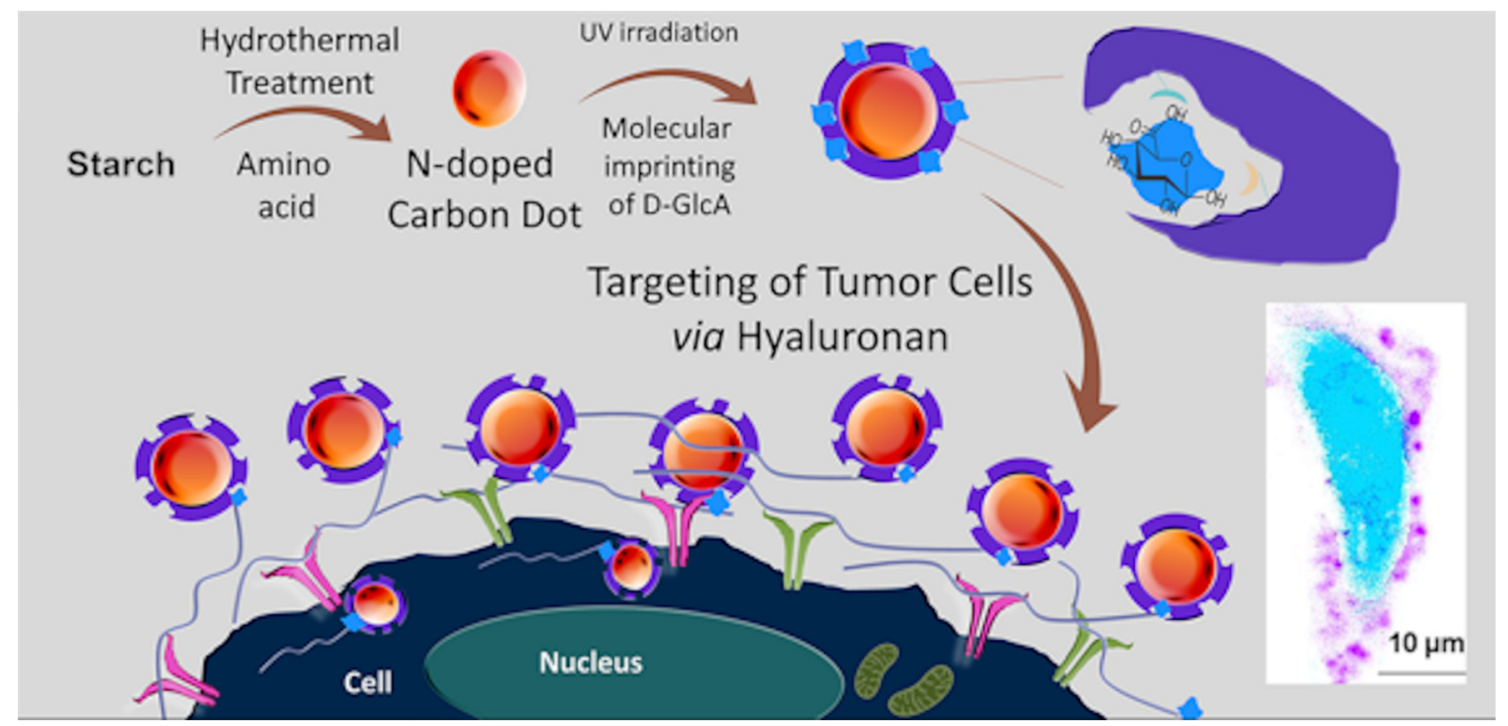

Figure 11. Preparation of core-shell CD-MIPs for bioimaging of cancer cells. Reprinted (adapted) with permission from Demir, B.; Lemberger, M.M.; Panagiotopoulou, M.; Medina Rangel, P.X.; Timur, S.; Hirsch, T.; Tse Sum Bui, B; Wegener, J.; Haupt, K. ACS Appl. Mater. Interfaces 2018, 10, 3305-3313 [110]. Copyright 2018 American Chemical Society.

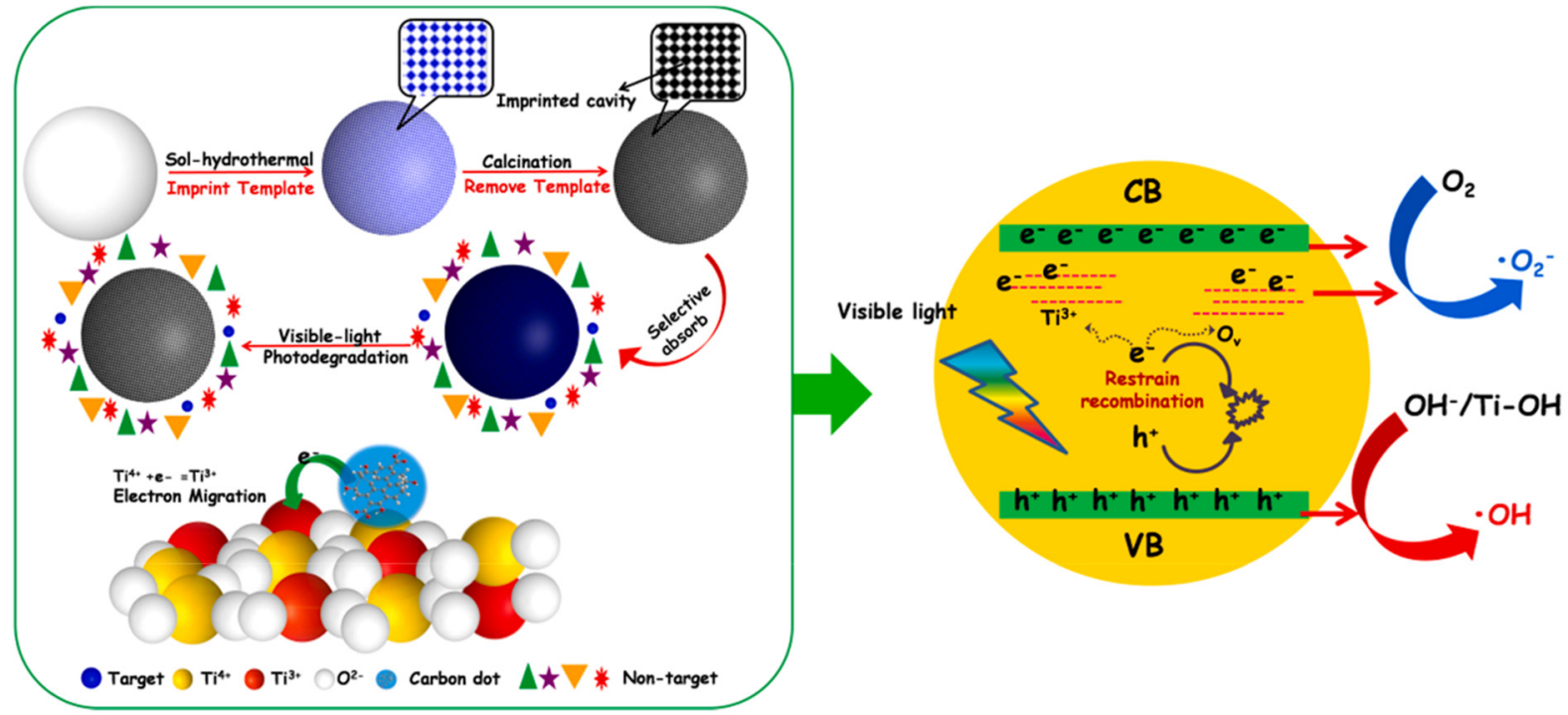

Figure 12. Schematic description of electron transition and photocatalytic process of $\mathrm{MIP}-\mathrm{TiO}_{2-\mathrm{x}} / \mathrm{CDs}$ under visible light. Reproduced from the work in [26] with permission from Elsevier.

\subsection{Cyclodextrins}

Starch represents a low-cost biomass resource that can be easily converted into valuable materials through eco-friendly processes with low environmental impact. Enzymatic conversion of starch sources like potato, corn, rice, tapioca, and wheat [111-113] determines the formation of cyclodextrins that represent natural polymers rich in active functional groups that can establish good affinities with numerous organic and inorganic compounds. Cyclodextrins are a family of cyclic oligosaccharides composed from $\beta$-(1,4)-linked glucopyranose subunits. Depending on the number of sugar units involved, cyclodextrins can be classified in $\alpha-, \beta-$, and $\gamma$-cyclodextrins $(\alpha-, \beta-, \gamma-C D s)$ that contain respectively six, seven and eight glucopyranose subunits [114]. The diameter of cyclodextrins enhances with the number of monomers involved in their structure, assuming a characteristic form of a truncated cone with the presence of hydrophilic groups oriented outside the cone and hydrophobic groups inside. Thanks to their unique properties to form inclusions of specific 
guest molecules, in the last decade they were used in different application fields such as enantiomer separation and drug delivery [115]. Moreover, all functional groups present in cyclodextrins can be easily modified in order to introduce more desired functional groups to modulate selectivity, solubility, etc. These characteristics make cyclodextrins suitable for their use as functional monomers in MIP technology. In particular, $\beta$-CDs are the most applied in MIP because their poor solubility in water facilitates its low-cost recovery through crystallization, compared with $\alpha$ - and $\gamma$-CDs that require expensive and time-consuming chromatographic technologies. Moreover, its chemical structure presents more discrimination ability, and thus eligiblity for MIP preparation [115]. Different works showed that the presence of cyclodextrins enhances the efficiency and the selectivity of the MIP towards the template molecule [116,117]. Finally, the hydrophilic groups present outside of cyclodextrins, improve the application of cyclodextrins-based MIPs in aqueous media [118], overcoming one of the main limitations of MIPs.

In the last decade, some reviews were published on the use of cyclodextrins in MIP preparation, pointing out the interest of the scientific community about this topic $[115,118,119]$. Very recently, Zhao et al. focused their work on the advances on cyclodextrins-based MIP applications ranging from their use in separation science, sensing and drug delivery [118].

Cyclodextrins can be used directly to act as specific functional monomers in MIP preparation [120-122] or can be modified in order to enhance the interactions with the template molecule. Moreover, they can also be used as binary functional monomers in combination with other monomers [123-129]. A common modification used consists in the addition of acryloyl and allyl moieties [115,130-133]. A complete description of different synthetic routes to modify cyclodextrins was widely discussed from Zhao [118]. For this reason, we will describe only some recent works highlighting the possible use of cyclodextrins as functional monomers and supporting materials in MIPs with interesting applications.

An application field widely studied regards the research of innovative materials for environmental remediation of pollutants. To this aim, a recent work conducted by Mamman et al. concerned the use of a modified $\beta-C D$ as functional monomer, to prepare a magnetic MIP (MMIP) for bisphenol A (BPA) retention in aqueous media [117]. First, MAA- $\beta$-CD was synthesized by a classical synthetic route mixing MAA, $\beta-\mathrm{CD}$ and toluene 2,4-diisocyanate $(0.5 / 0.5 / 1 ; v / v / v)$ in dimethylacetamide (DMAC). Then, the magnetic polymer was prepared using MAA- $\beta-C D$ as functional monomer, BPA as template, trimethylolpropane trimethacrylate (TRIM) as crosslinking agent, and benzoyl peroxide (BPO) as initiator. In order to confer magnetic properties, the particles obtained were mixed with iron chloride in water. A magnetic NIP (MNIP MAA- $\beta C D$ ) was also prepared using the same synthetic route but without the presence of the template molecule. Moreover, in order to evaluate the influence of $\beta$-CDs in the imprinting capacity, a control polymer was prepared using only MAA as functional monomer. Adsorption performances were conducted in PBA water solution. Different parameters that influence the adsorption capacity of polymers prepared were analyzed. In particular, $\mathrm{pH}$, concentration of polymeric particles, contact time, and temperature were studied. The results obtained, comparing the adsorption performance of all polymers prepared, showed an optimum adsorption time of $60 \mathrm{~min}$ at $\mathrm{pH} 8$ with an analyte concentration of $10 \mathrm{mg} \mathrm{L}^{-1}$ and an adsorbent dose of $20 \mathrm{mg}$ for MNIP MAA- $\beta C D$. It is interesting to note how the presence of $\beta$-CDs influences the adsorption performance enhancing their capability to trap BPA. These results can be due to the possibility of BPA to form an inclusion complex with $\beta-C D$ during the recognition process enhancing the adsorption behavior. Indeed, compared to MMIP MAA, MMIP MAA- $\beta C D$ showed higher initial sorption rates $\left(7.4906 \mathrm{mg} \mathrm{g}^{-1} \mathrm{~min}\right)$ obtained from a pseudo-second-order kinetics model with low values of time required for the adsorption. This can be attributable to the presence of $\beta-C D$ moiety in the internal surface of MMIP MAA- $\beta C D$ which determines the presence of pore with large size and low volume of polymeric matrix improving the mass transfer of BPA [117].

An innovative approach to prepare functionalized cyclodextrins consists in the possibility to use luminescent materials to modify their hydroxyl groups in order to form a probe 
capable to change its optical signal in the presence of microenvironmental changes due to the bond with a target compound. An interesting work made by Shi and co-workers [134] describes the preparation of surface-imprinted $\beta$-cyclodextrin-functionalized carbon nitride nanosheets (CNNS) for fluorometric determination of sterigmatomycin. CNNS were obtained from the exfoliation of graphitic carbon nitride $\left(g-C_{3} N_{4}\right)$ and possess interesting fluorescence properties. In a first step, after preparation of CNNS, $\beta-C D$ were modified by liquid phase exfoliation in order to obtain $\beta$-CD/CNNS [135] that was successively used as support for sterigmatomycin-MIP preparation (Figure 13).
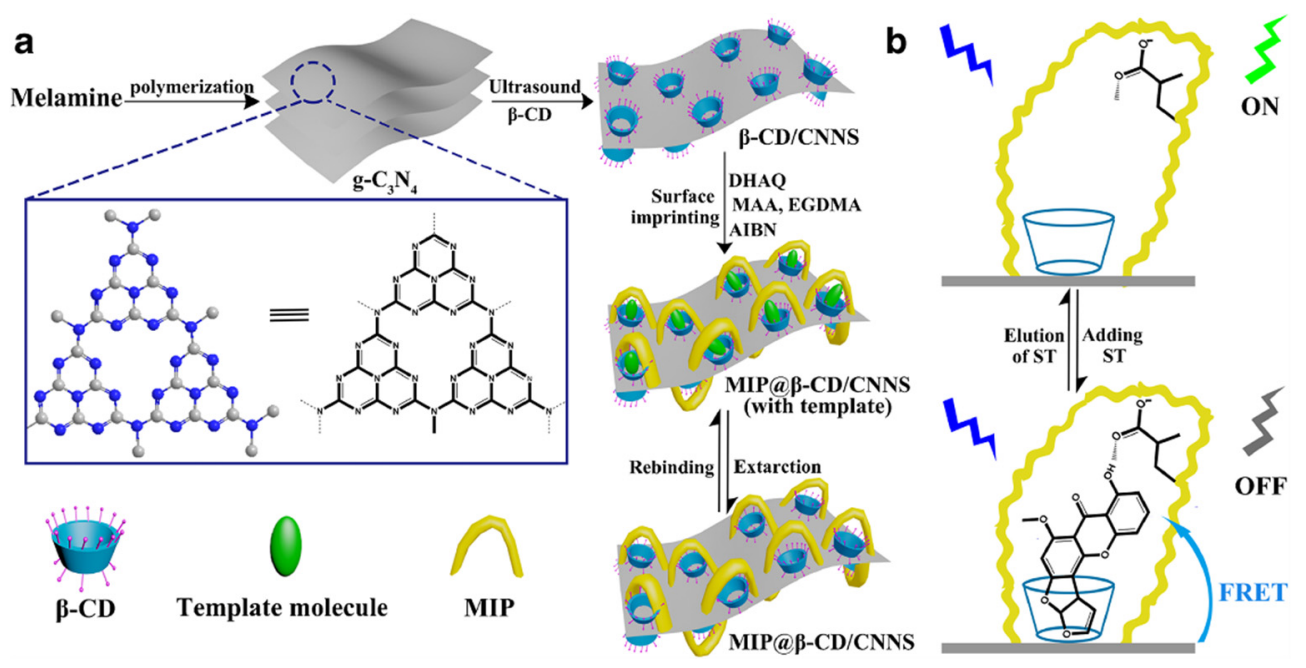

Figure 13. Schematic representation of the synthesis of MIP@ $\beta$-CD-modified carbon nitride nanosheets (CNNS) (a); and its application (b). Reproduced from the work in [134] with permission from Springer Nature.

$\beta-C D / C N N S$ were first dissolved in dimethylformamide and stirred with the template at $60^{\circ} \mathrm{C}$ for $3 \mathrm{~h}$. After, functional monomer (MAA), crosslinking agent (EGDMA), and the initiator 2-2'-azobisisobutyronitrile (AIBN) were added and stirred to obtain an innovative MIP@ $\beta-C D / C N N S$ for fluorescent detection of sterigmatomycin. Adsorption studies demonstrated a larger adsorption capacity of MIP@ $\beta-C D / C N N S\left(86 \mathrm{mg} \cdot \mathrm{g}^{-1}\right)$ compared with the corresponding NIP and with the different components of polymer $\left(\beta-\mathrm{CD}, \mathrm{g}-\mathrm{C}_{3} \mathrm{~N}_{4}\right.$ and $\beta-C D / C N N S)$. Moreover, MIP@ $\beta-C D / C N N S$ shower less time $(25 \mathrm{~min})$ to reach an equilibrium in the adsorption compared to the corresponding NIP. Also in this case, this is due to the presence of $\beta$-CDs in the polymeric matrix that determine a fast mass transfer rate of the surface imprinted polymer. Then, fluorescence resonance energy transfer (FRET) technology was used to verify the real use of MIP@ $\beta-C D / C N N S$ as probe for detection of STG.

Results obtained revealed excellent photoelectric properties of the MIP prepared that can be used as optical probe but also as an efficient adsorbent and catalyst material for more applications.

As punctually described from Zhao, cyclodextrin-based MIPs were widely used to prepare electrochemical sensors [118]. Often B-CDs are used as functional monomer, can be electropolymerized on electrode surfaces without the addition of initiators and crosslinking agents and it can act as supporting material in MIP preparation.

A recent work describes a molecularly imprinted polymer sensor for horseradish peroxidase (HRP) prepared through an electropolymerization of $B-C D$ s on the surface of a glassy carbon electrode [136]. In this study, Poly beta-cyclodextrins $\mathrm{P}(\mathrm{B}-\mathrm{CDs})$ were used as supporting material and the reaction was carried out combining electropolymerization of $\mathrm{B}-\mathrm{CD}$ s and the molecular imprinted technology. Electropolymerization represents a phenomenon that requires the oxidation of a monomer to form a radical cation applying an oxidation potential. In this context, $\beta$-CDs (Figure 14). 


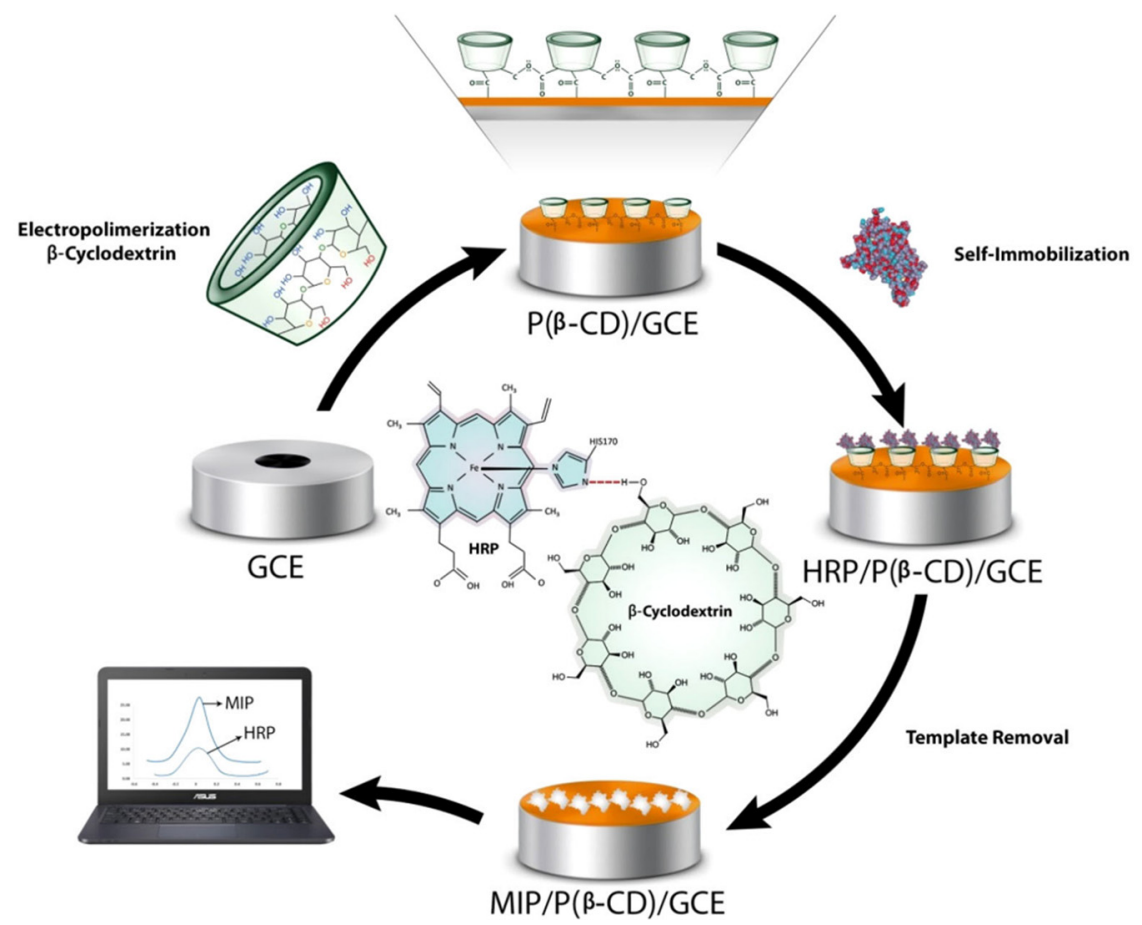

Figure 14. MIP / $P(\beta-C D) / G C E$ preparation and detection of HRP. Reproduced from the work in [136] with permission from Wiley.

The results obtained showed excellent electro-conductivity of $\beta$-CDs that facilitated electron transfer of $\mathrm{P}(\mathrm{B}-\mathrm{CD})$. The imprinted polymer sensor showed good detection performance of HRP with a linear range between $0.1 \mathrm{mg} \mathrm{mL}^{-1}$ to $10 \mathrm{ng} \mathrm{mL}^{1}$ and LOD of $2.23 \mathrm{ng} \mathrm{mL}^{-1}$. Moreover, the imprinted biosensor, applied to real samples, showed a good electro-catalytic activity towards the reduction of $\mathrm{H}_{2} \mathrm{O}_{2}$ that was evaluated in a concentration range of 1 to $15 \mu \mathrm{M}$ with a detection limit of $0.4 \mu \mathrm{M}$ using chronoamperometry technique. For these reasons, the developed bio imprinted sensors can be used as platform for biomedical analysis of hydrogen peroxide concentration in biological matrices such as human plasma.

\subsection{Biomass Waste Extracts in MIPs Preparation}

Other important natural starting materials obtained from agri-food processing are waste extracts. There are several works and reviews that have focused their attention on the possible use of waste extracts as green chemicals to reduce environmental pollution [137-142]. Their compositions are characterized by numerous important biomolecules such as sugars and polyphenols that can act as reducing agents for metal salts, but also as natural stabilizers. The action of these two classes of biomolecules determines the formation of stable metal nanoparticles obtained through an eco-friendly process which reflects the principles of green chemistry. In the last years, there are a lot of works that focused their research on the use of waste extracts as a driving force for the design of greener and safer protocols for metal nanoparticles preparation [138,142-146]. Recently, the advantages of metal nanoparticles were combined with the specificity of MIPs in order to confer higher sensitivity, magnetic, and also optical properties due to the plasmon resonance typical of metal nanoparticles such as gold and silver.

A common synthetic route to prepare metal nanoparticles requires the use of a chemical reducing agents such as borohydrides, sodium borohydride that are harmful for the environment and limited the use of nanoparticles obtained in medical application because of their toxicity or safer sodium citrate and alcohols; but, in any case, chemical substances need to be added to prevent aggregation processes. Recently, some works combining the advantages of metal nanomaterials with the selectivity of MIPs were published [146-150]. 
Only one of these was made using metal green nanoparticles obtained from waste extracts in MIPs preparation [150].

In their work, López et al. prepared, for the first time, green iron nanoparticles using eucalyptus extract (GNP) to confer magnetic properties at a series of MIPs selective for seven non-steroid anti-inflammatory drugs (diclofenac sodium, indomethacin, acetaminophen, naproxen, ketoprofen, ibuprofen, and mefenamic acid) and their adsorption performances were compared with the same imprinted polymers prepared using iron nanoparticles synthesized by chemical route (CNP) [150-152]. GNP were prepared in a bath at $70{ }^{\circ} \mathrm{C}$, adding the eucalyptus extract to an iron solution. After, GNP was precipitated by the addition of $\mathrm{NH}_{3}$, neutralized with ultrapure water and dried under vacuum. Then magnetic MIP-GNP and magnetic MIP-CNP were prepared by mixing the template and iron nanoparticles (GNP or CNP) in a porogenic solvent. After the addition of the functional monomer, the crosslinking agent (EGDMA) and the initiator (AIBN) the reaction was conducted at $60{ }^{\circ} \mathrm{C}$. Comparing the adsorption performances of all MIPs prepared it is obvious the influence exerted from GNP in the binding of the template. Although magnetic MIP-CNP reaches equilibrium in shorter times than magnetic MIP-GNP, the presence of organic matter in the extract solution acts as capping agent enhancing the adsorption performance of MIP-GNP. Indeed, the adsorption capacity with green nanoparticles was increased by more than $100 \%$ in all cases, in relation to the adsorption value of the chemical nanoparticles.

In another work lemon juice was used as natural reducing agent instead of chemical compounds such as sodium borohydride to prepare vinyl modified reduced graphene oxide-based magnetic and bimetallic (Fe/Ag) nanodendrite (RGO@BMNDs) as innovative platform for MIP technology [151]. Citrus plants contain high amounts of antioxidant compounds and can act as low cost, easily available, and natural reducing source. Firstly, Graphene Oxide (GO) was prepared from graphene powder through an oxidation process by using strong oxidizing agents. In the final step graphene sheets were obtained and used as support for the synthesis of bimetallic (Fe/Ag) nanodendrites through a facile Fe nanoseed-induced method. At first, zero valent iron was formed on the RGO surface by using lemon juice as natural reducing agent, followed from a displacement reaction that partially replace the Fe with $\mathrm{Ag}$, in order to obtain a bimetallic nanodendrite structure (Figure 15). These steps were conducted without the use of harmful compounds or harsh physical conditions respecting the principle of green chemistry. Then, synthesized RGO@BMNDs with high catalytic activity and adsorption capacity, were used as platform for the preparation of an imprinted polymer modified electrochemical sensor for detection in human blood serum and in plasma samples of ultra-trace of the analyte pyrazinamide (PZA), a drug for the control of tuberculosis disease, with a limit of detection equal to $6.65 \mathrm{pg} \mathrm{L}^{-1}$.

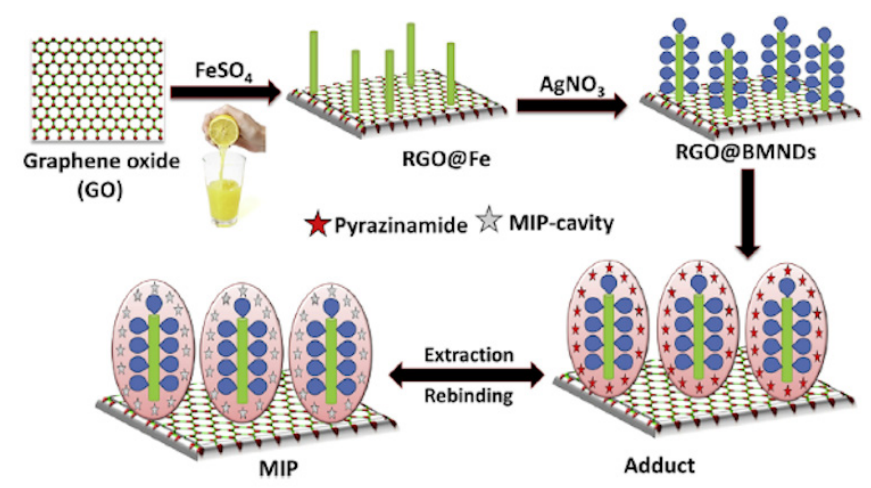

Figure 15. Graphical representation for the synthesis of imprinted reduced graphene oxide@bimetallic nanodendrites. Reproduced from [151] with permission from Elsevier. 
A facile and low-cost photosynthetic route was used from Essawy to prepare silver imprinted zinc nanoparticles (AGZnONPs) by using aqueous extract of guava leaves for nanoparticles preparation instead of undesirable chemical reagents. In particular, $\mathrm{AgNO}_{3}$ and $\mathrm{ZnO}$ aqueous solution were added dropwise to guava leaves extract and heated at $70{ }^{\circ} \mathrm{C}$ under vigorous stirring. Nanoparticle formation is confirmed from the color change to brownish and their photocatalytic activity was demonstrated estimating the degradation rate of methylene blue dye [152].

Other biomass resources obtained from the agri-food industry were used in some works as starting material to prepare new biobased MIPs [153,154].

In a recent work epoxidized soybean oil (ESOA) was used as an innovative crosslinking agent in the preparation of a biobased MIPs employed as a biopesticide delivery system [153]. The crosslinking agent represents the major component of MIP and for this reason its substitution with natural compounds represent a great challenge. Due to their composition, vegetable oils are considered today renewable natural materials useful in MIPs preparation and can confer stability to the polymers. In this work, resveratrol, with important antifungal activity against several phytopathogens, was used as template and mixed with functional monomer (4-vinylpyridine or 1-vinylpyridine), crosslinking agent (EOSA or EGDMA), and initiator (AIBN) in chloroform. The reaction was conducted for $50{ }^{\circ} \mathrm{C}$ for $24 \mathrm{~h}$. Resveratrol-MIP using EOSA was also prepared by emulsion polymerization and the results were compared. Results obtained showed a maximum adsorption capacity of EOSA-base MIP, prepared by bulk polymerization, equal to $34.2 \mu \mathrm{mol} \mathrm{g}^{-1}$ that was higher than the adsorption values obtained with the corresponding imprinted polymer prepared using EGDMA instead of EOSA. Moreover, it was demonstrated the ability of EOSA-based MIP to release resveratrol in aqueous medium, exhibiting high sensitivity to a fungal lipase, due to the enzymatic degradability of the polymer. This result is very interesting for future application in agricultural treatments because it suggests eco-friendly characteristics of the material that can be naturally degraded.

Starch extracted from Solanum tuberosum was used as copolymer with polyvinyl alcohol (PVA) for the preparation of an ion imprinted Starch/PVA polymers for Thorium (IV) adsorption [154]. Starch contains a large numbers of hydroxyl groups and was incorporated in an ionic liquid (1-butyl 3-methyl-imidazolium tetrafluoroborate ionic liquid), with PVA and glutaraldehyde (crosslinker) and the reaction was conducted at $45^{\circ} \mathrm{C}$. After addition of thorium, the solution was subjected to electrospinning at $11.5 \mathrm{kV}$ voltage and $0.54 \mathrm{~mL} \mathrm{~min}^{-1}$ flow rate. Nanofibers were collected and treated with $\mathrm{HCl}(37 \%)$ solution at $\mathrm{pH} 5$ to eliminate thorium ions and then washed with ultrapure water. Results obtained suggest a high sorption efficiency $(87 \%)$ of the polymer at ecologically optimum conditions, at $\mathrm{pH} 7$ and $0.5 \mathrm{~g}$ of adsorbent dose, with a best compliance with Langmuir model.

\subsection{Summary}

All the studies reported in this review on various waste sources used in MIPs preparation have been summarized in Table 1 .

Table 1. An overview of the reported studies on the use of various waste sources in MIPs preparation.

\begin{tabular}{|c|c|c|c|c|c|}
\hline Waste Material & MIP Composition & MIP Strategy & Target Analyte & Application & Ref. \\
\hline Chitosan & $\begin{array}{l}\text { Core-shell CS-based } \\
\text { magnetic MIPs }\end{array}$ & Surface imprinting & Acrylamide & $\begin{array}{l}\text { Clean-up and pre-concentration } \\
\text { in biscuit samples }\end{array}$ & [48] \\
\hline Chitosan & $\begin{array}{l}\text { Core-shell CS-based } \\
\text { magnetic MIPs }\end{array}$ & Surface imprinting & Valsartan Losartan & $\begin{array}{l}\text { Simultaneous pre-concentration } \\
\text { and determination from urine } \\
\text { samples }\end{array}$ & [49] \\
\hline Chitosan & $\begin{array}{l}\text { MIP on the surface of } \\
\text { magnetic CS/graphene oxide }\end{array}$ & Surface imprinting & Fluoxetine & $\begin{array}{c}\text { Separation and } \\
\text { pre-concentration in } \\
\text { pharmaceutical formulation, } \\
\text { human urine and } \\
\text { environmental water sample }\end{array}$ & [50] \\
\hline Chitosan & $\begin{array}{l}\text { Core-shell chitosan gold } \\
\text { nanoparticles/decorated MIP }\end{array}$ & Surface imprinting & $\begin{array}{l}\text { Ciprofloxacin } \\
\text { antibiotic }\end{array}$ & $\begin{array}{l}\text { Electrochemical biomimetic } \\
\text { sensor }\end{array}$ & [51] \\
\hline
\end{tabular}


Table 1. Cont.

\begin{tabular}{|c|c|c|c|c|c|}
\hline Waste Material & MIP Composition & MIP Strategy & Target Analyte & Application & Ref. \\
\hline Chitosan & $\begin{array}{c}\text { IIPs membrane } \\
\text { of gelatin/8- } \\
\text { hydroxyquinoline/CS }\end{array}$ & $\begin{array}{l}\text { Crosslinking of gelatin, } \\
\text { 8-hydroxyquinoline and } \\
\text { CS }\end{array}$ & $\mathrm{Cu}(\mathrm{II})$ & Removal from aqueous solution & [52] \\
\hline Chitosan & $\begin{array}{l}\text { Ion imprinted CS } \\
\text { microspheres }\end{array}$ & Microfluidic technique & $\mathrm{Ca}(\mathrm{II})$ & $\begin{array}{l}\text { Removal of } \mathrm{Cu}(\mathrm{II}), \mathrm{Cd}(\mathrm{II}) \text { and } \\
\mathrm{Pb}(\mathrm{II}) \text { from wastewater }\end{array}$ & [53] \\
\hline Chitosan & $\begin{array}{l}\text { Ion imprinted thiourea } \\
\text { modified CS microspheres }\end{array}$ & Microfluidic technique & $\mathrm{Cu}(\mathrm{II})$ & Removal from wastewater & [54] \\
\hline Cellulose & $\begin{array}{c}\text { Water compatible } \\
\text { CMC/AA/2- } \\
\text { hydroxyethylmethacrylate }\end{array}$ & $\begin{array}{l}\text { Crosslinking of CMC, } \\
\text { AA, 2-hydroxyethylmeth } \\
\text { acrylate }\end{array}$ & Furosemide & Slow release in drug delivery & [70] \\
\hline Cellulose & $\begin{array}{c}\text { Polypyrrole/Sulphur-CMC } \\
\text { IIPs }\end{array}$ & $\begin{array}{l}\text { Glassy carbon electrode } \\
\text { modified by electro- } \\
\text { polymerizing of pyrrole } \\
\text { and Sulphur-IIPs drop } \\
\text { coated }\end{array}$ & $\mathrm{Hg}$ (II) & $\begin{array}{c}\text { Electrode } \\
\text { modifier for the electrochemical } \\
\text { detection of } \mathrm{Hg}(\mathrm{II})\end{array}$ & [77] \\
\hline Cellulose & $\begin{array}{l}\text { MIP/CMC coupled with } \\
\text { magnetic material }\end{array}$ & $\begin{array}{l}\text { Surface imprinting on } \\
\text { magnetic CMC } \\
\text { nanocrystals }\end{array}$ & Fluoroquinolones & $\begin{array}{l}\text { Adsorption and determination } \\
\text { in water }\end{array}$ & [56] \\
\hline Cellulose & $\begin{array}{c}\text { Photo-responsive } \\
\text { cellulose-based imprinted } \\
\text { polymer }\end{array}$ & $\begin{array}{l}\text { Surface-initiated atom } \\
\text { transfer radical } \\
\text { polymerization }\end{array}$ & $\begin{array}{l}\text { 2,4-dichloropheno } \\
\text { xyacetic acid }\end{array}$ & $\begin{array}{l}\text { Photo responsive sorbent } \\
\text { material }\end{array}$ & [73] \\
\hline $\begin{array}{l}\text { Cotton wool } \\
\text { cellulose }\end{array}$ & $\begin{array}{c}\text { Hierarchical silica-based ion } \\
\text { imprinted mesoporous } \\
\text { polymers }\end{array}$ & Via dual template method & $\mathrm{Cd}(\mathrm{II})$ and $\mathrm{Pb}(\mathrm{II})$ & $\begin{array}{l}\text { Micro solid phase simultaneous } \\
\text { extraction from river water and } \\
\text { fish muscles }\end{array}$ & [71] \\
\hline $\begin{array}{l}\text { Rice straw } \\
\text { cellulose }\end{array}$ & Straw-supported IIPs & $\begin{array}{l}\text { Surface imprinting } \\
\text { combined with } \\
\text { AGET-ATRP }\end{array}$ & $\mathrm{La}(\mathrm{III})$ & Sorbent material & [85] \\
\hline $\begin{array}{l}\text { Basswood } \\
\text { cellulose }\end{array}$ & $\begin{array}{l}\text { 3D-macroporous wood-based } \\
\text { membrane decorated with } \\
\text { imprinted domains }\end{array}$ & $\begin{array}{c}\text { Two-step-temperature } \\
\text { free radical } \\
\text { polymerization }\end{array}$ & $\mathrm{Nd}(\mathrm{III})$ & Sorbent material & [82] \\
\hline $\begin{array}{c}\text { Agricultural } \\
\text { waste biochar }\end{array}$ & $\begin{array}{l}\text { Activated biochar } \\
\text { functionalized with } \\
\text { 3-mercaptopropyltrimeth } \\
\text { oxysilane-based IIPs }\end{array}$ & Surface imprinting & $\mathrm{Cd}(\mathrm{II})$ & $\begin{array}{l}\text { Selective removal from } \\
\text { wastewater }\end{array}$ & [91] \\
\hline $\begin{array}{l}\text { Waste tea } \\
\text { derived carbon }\end{array}$ & $\begin{array}{l}\text { Activated carbon support of } \\
\text { dopamine-based imprinted } \\
\text { polymer with multi-boronic } \\
\text { acid sites }\end{array}$ & Surface imprinting & Albumin & $\begin{array}{l}\text { Selective capture of } \\
\text { glycoprotein }\end{array}$ & [94] \\
\hline $\begin{array}{l}\text { Sunflower } \\
\text { heads }\end{array}$ & $\begin{array}{l}\text { Activated carbon support of } \\
\text { acrylamide-based imprinted } \\
\text { polymer }\end{array}$ & Surface imprinting & $\mathrm{CO}_{2}$ & $\begin{array}{l}\text { Selective adsorption in the } \\
\text { presence of } \mathrm{H}_{2} \mathrm{O} \text { and in } \\
\text { simulated flue gas }\end{array}$ & [92] \\
\hline $\begin{array}{c}\text { Teak } \\
\text { ligno-cellulosic } \\
\text { material }\end{array}$ & $\begin{array}{c}\text { Activated } \\
\text { carbon/MIP/parafin }\end{array}$ & $\begin{array}{l}\text { By mixing paraffin, MIP } \\
\text { and activated carbon }\end{array}$ & Melamine & Electrochemical biosensor & [93] \\
\hline $\begin{array}{l}\text { Sweet potato } \\
\text { peels }\end{array}$ & MIP-coated CDs & Sol-gel polymerization & Oxytetracycline & $\begin{array}{l}\text { Fluorescence probe for specific } \\
\text { recognition and sensitive } \\
\text { detection in honey }\end{array}$ & [105] \\
\hline Longan peels & $\begin{array}{l}\text { CDs coupled with restricted } \\
\text { access materials } \\
\text { and MIPs }\end{array}$ & $\begin{array}{c}\text { Multifunctional } \\
\text { composites by a simple } \\
\text { polymerization method }\end{array}$ & Metronidazole & $\begin{array}{l}\text { Fluorescence probe for specific } \\
\text { recognition and sensitive } \\
\text { detection in serum }\end{array}$ & [107] \\
\hline Mango peels & CDs encapsulated into MIPs & Sol-gel polymerization & Mesotrione & $\begin{array}{l}\text { Fluorescent biosensor for } \\
\text { detection in corn }\end{array}$ & [108] \\
\hline $\begin{array}{l}\text { Rosemary } \\
\text { leaves }\end{array}$ & CDs embedded in silica MIPs & $\begin{array}{l}\text { Reverse microemulsion } \\
\text { and surface imprinting }\end{array}$ & Thiabendazole & $\begin{array}{l}\text { Optical probe for quantification } \\
\text { in apple, orange, and tomato } \\
\text { juices }\end{array}$ & [109] \\
\hline Starch & MIPs coated CDs & $\begin{array}{l}\text { Epitope approach with } \\
\text { glucuronic acid }\end{array}$ & Hyaluronan & $\begin{array}{c}\text { Cancer cell biotargeting and } \\
\text { bioimaging }\end{array}$ & [110] \\
\hline Lignite & $\begin{array}{l}{\mathrm{MIP}-\mathrm{TiO}_{2-\mathrm{x}}} / \mathrm{CDs} \\
\text { nanocomposite }\end{array}$ & $\begin{array}{l}\text { Two-step hydrothermal } \\
\text { calcination method }\end{array}$ & Methylene blue & $\begin{array}{c}\text { Photocatalytic degradation in } \\
\text { wastewater }\end{array}$ & [26] \\
\hline
\end{tabular}


Table 1. Cont.

\begin{tabular}{ccccc}
\hline Waste Material & MIP Composition & MIP Strategy & Target Analyte & Application \\
\hline Cyclodextrins & Magnetic MIP of MAA- $\beta$ CD & Bulk polymerization & Bisphenol A & $\begin{array}{c}\text { Magnetic sorbent for pollutant } \\
\text { removal from water }\end{array}$ \\
\hline [117]
\end{tabular}

\section{Conclusions}

This review provides an extensive overview on the use of different kind of biomass waste derivatives as backbone materials in MIP preparation, pointing out the most recent works that developed greener analytical protocols of synthesis to reduce environmental pollution. A complete description of strategies to replace typical highly toxic chemicals generally required in MIPs, with natural polymers obtained from biomass wastes, such as chitosan, cellulose, or cyclodextrins, was made. In particular, it was underlined the possibility to modify these natural resources in order to obtain new green substrates for MIPs preparation that can be used as innovative functional monomers, initiator, crosslinking agent, or supporting materials. Activated carbon and carbon dots were also deepened for their important chemical properties, the high availability and low costs for production and used in association to MIPs in order to enhance their selective absorption or their electrochemical properties, respectively.

The works analyzed in this review show how the introduction of biomass wastes in MIPs preparation can determine an increase of adsorption and selectivity performance and also greater sensitivity and morphology control, compared to the same polymers prepared using common synthetic routes.

We hope that the results highlighted in this review will be useful to stimulate the use of more sustainable preparation strategies for MIP production in order to exploit eco-friendly resources, such as biomass waste, easily available in nature.

Although numerous examples of preparation of MIPs by using different biomass waste have been recently described in literature, many challenges still exist. First of all, the use of biomass waste in combination with other materials, such as nanoparticles or magnetic materials, represent a great potential since it allows to obtain novel composite materials with unique properties. However, it requires to apply improvement in the green concept to the whole design process. Second, it is still a big challenge to realize the large-scale production of high-quality polymers or compounds obtained from biomass waste. 
Author Contributions: Conceptualization, writing-original draft preparation, supervision, R.D.S. and L.M.; review and editing, G.M. and E.B. All authors have read and agreed to the published version of the manuscript.

Funding: This research received no external funding.

Institutional Review Board Statement: Not applicable.

Informed Consent Statement: Not applicable.

Conflicts of Interest: The authors declare no conflict of interest.

\section{References}

1. Anastas, P.T.; Warner, J.C. Green Chemistry: Theory and Practice; Oxford University Press: New York, NY, USA, 1998.

2. Anastas, P.; Eghbali, N. Green Chemistry: Principles and Practice. Chem. Soc. Rev. 2010, 39, 301-331. [CrossRef]

3. Tang, S.; Bourne, R.; Smith, R.; Poliakoff, M. The 24 principles of green engineering and green chemistry: "IMPROVEMENTS PRODUCTIVELY". Green Chem. 2008, 10, 268-269. [CrossRef]

4. Sheldon, R.A. Fundamentals of green chemistry: Efficiency in reaction design. Chem. Soc. Rev. 2012, 41, 1437-1451. [CrossRef]

5. Sheldon, R.A. Metrics of green chemistry and sustainability: Past, present, and future. ACS Sustain. Chem. Eng. 2018, 6, 32-48. [CrossRef]

6. Garedew, M.; Lin, F.; Song, B.; DeWinter, T.M.; Jackson, J.E.; Saffron, C.M.; Lam, C.H.; Anastas, P.T. Greener routes to biomass waste valorization: Lignin transformation through electrocatalysis for renewable chemicals and fuels production. ChemSusChem 2020, 13, 4214-4237. [CrossRef]

7. Shanks, B.H.; Keeling, P.L. Bioprivileged molecules: Creating value from biomass. Green Chem. 2017, 19, 3177-3185. [CrossRef]

8. Cerda, A.; Artola, A.; Barrena, R.; Font, X.; Gea, T.; Sánchez, T. Innovative production of bioproducts from organic waste through solid-state fermentation. Front. Sustain. Food Syst. 2019, 3, 63. [CrossRef]

9. Zuin, V.G.; Ramin, L.Z. Green and sustainable separation of natural products from agro-industrial waste: Challenges, potentialities, and perspectives on emerging approaches. Top Curr. Chem. 2018, 376, 3. [CrossRef] [PubMed]

10. Jha, A.; Kumar, A. Biobased technologies for the efficient extraction of biopolymers from waste biomass. Bioprocess Biosyst. Eng. 2019, 42, 1893-1901. [CrossRef]

11. Pistone, A.; Espro, C. Current trends on turning biomass wastes into carbon materials for electrochemical sensing and rechargeable battery applications. Curr. Opin. Green Sustain. Chem. 2020, 26, 100374. [CrossRef]

12. Yahya, M.A.; Al-Qodah, Z.; Zanariah Ngah, C.W. Agricultural bio-waste materials as potential sustainable precursors used for activated carbon production: A review. Renew. Sustain. Energy Rev. 2015, 46, 218-235. [CrossRef]

13. Kang, C.; Huang, Y.; Yang, H.; Yan, X.F.; Chen, Z.P. A review of carbon dots produced from biomass wastes. Nanomaterials 2020, 10, 2316. [CrossRef] [PubMed]

14. Abbas, A.; Mariana, L.T.; Phan, A.N. Biomass-waste derived graphene quantum dots and their applications. Carbon 2018, 140, 77-99. [CrossRef]

15. Vasapollo, G.; Del Sole, R.; Mergola, L.; Lazzoi, M.R.; Scardino, A.; Scorrano, S.; Mele, G. Molecularly imprinted polymers: Present and future perspective. Int. J. Mol. Sci. 2011, 12, 5908-5945. [CrossRef]

16. Chen, L.; Wang, X.; Lu, W.; Wu, X.; Li, J. Molecular imprinting: Perspectives and applications. Chem. Soc. Rev. 2016, 45, 2137. [CrossRef] [PubMed]

17. Culver, H.A.; Steichen, S.D.; Peppas, N.A. A Closer look at the impact of molecular imprinting on adsorption capacity and selectivity for protein templates. Biomacromolecules 2016, 17, 4045-4053. [CrossRef]

18. Janczura, M.; Lulínski, P.; Sobiech, M. Imprinting technology for effective sorbent fabrication: Current state-of-art and future prospects. Materials 2021, 14, 1850. [CrossRef]

19. Ansari, S. Combination of molecularly imprinted polymers and carbon nanomaterials as a versatile biosensing tool in sample analysis: Recent applications and challenges. TrAC Trends Anal. Chem. 2017, 93, 134-151. [CrossRef]

20. Ansari, S.; Masoum, S. Recent advances and future trends on molecularly imprinted polymer-based fluorescence sensors with luminescent carbon dots. Talanta 2021, 223, 121411. [CrossRef] [PubMed]

21. Ashley, J.; Shahbazi, M.-A.; Kant, K.; Chidambar, V.A.; Wolff, A.; Bang, D.D.; Sun, Y. Molecularly imprinted polymers for sample preparation and biosensing in food analysis: Progress and perspectives. Biosens. Bioelectron. 2017, 91, 606-615. [CrossRef]

22. Ahmad, O.S.; Bedwell, T.S.; Esen, C.; Garcia-Cruz, A.; Piletsky, S.A. Molecularly imprinted polymers in electrochemical and optical sensors. Trends Biotechnol. 2019, 37, 294-309. [CrossRef]

23. Luliński, P. Molecularly imprinted polymers based drug delivery devices: A way to application in modern pharmacotherapy. A review. Mater. Sci. Eng. C 2017, 76, 1344-1353. [CrossRef]

24. Sharabi, D.; Paz, Y. Preferential photodegradation of contaminants by molecular imprinting on titanium dioxide. Appl. Catal. B Environ. 2010, 95, 169-178. [CrossRef]

25. Cantarella, M.; Mauro, A.D.; Gulino, A.; Spitaleri, L.; Nicotra, G.; Privitera, V.; Impellizzeri, G. Selective photodegradation of paracetamol by molecularly imprinted ZnO nanonuts. Appl. Catal. B Environ. 2018, 238, 509-517. [CrossRef] 
26. Yu, J.; Zhang, C.; Yang, Y.; Su, T.; Yi, G.; Zhang, X. Facile synthesis of molecularly imprinted black TiO $2-x /$ carbon dots nanocomposite and its recognizable photocatalytic performance under visible-light. Appl. Surf. Sci. 2021, 551, 149476. [CrossRef]

27. Bonatti, A.F.; De Maria, C.; Vozzi, G. Molecular imprinting strategies for tissue engineering applications: A review. Polymers 2021, 13, 548. [CrossRef] [PubMed]

28. Jablonský, M.; Majová, V.; Šima, J.; Hrobǒnová, K.; Lomenová, A. Involvement of deep eutectic solvents in extraction by molecularly imprinted polymers-A minireview. Crystals 2020, 10, 217. [CrossRef]

29. Viveiros, R.; Rebocho, S.; Casimiro, T. Green strategies for molecularly imprinted polymer development. Polymers 2018, 10, 306. [CrossRef]

30. Li, N.; Yang, H. Construction of natural polymeric imprinted materials and their applications in water treatment: A review. J. Hazard. Mater. 2021, 403, 123643. [CrossRef] [PubMed]

31. Madikizela, L.M.; Tavengw, N.T.; Tutuc, H.; Chimukac, L. Green aspects in molecular imprinting technology: From design to environmental applications. Trends Environ. Anal. Chem. 2018, 17, 14-22. [CrossRef]

32. Muxika, A.; Etxabide, A.; Uranga, J.; Guerrero, P.; de la Caba, K. Chitosan as a bioactive polymer: Processing, properties and applications. Int. J. Biol. Macromol. 2017, 105, 1358-1368. [CrossRef]

33. Zhang, L.; Zeng, Y.; Cheng, Z. Removal of heavy metal ions using chitosan and modified chitosan: A review. J. Mol. Liq. 2016, 214, 175-191. [CrossRef]

34. Ali, A.; Ahmed, S. A review on chitosan and its nanocomposites in drug delivery. Int. J. Biol. Macromol. 2018, 109, 273-286. [CrossRef]

35. LogithKumar, R.; KeshavNarayan, A.; Dhivya, S.; Chawla, A.; Saravanan, S.; Selvamurugan, N. A review of chitosan and its derivatives in bone tissue engineering. Carbohydr. Polym. 2016, 151, 172-188. [CrossRef] [PubMed]

36. Mujtaba, M.; Morsi, R.E.; Kerch, G.; Elsabee, M.Z.; Kaya, M.; Labidi, J.; Khawar, K.M. Current advancements in chitosan-based film production for food technology; A review. Int. J. Biol. Macromol. 2019, 121, 889-904. [CrossRef] [PubMed]

37. Kurita, K. Chitin and chitosan: Functional biopolymers from Marine Crustaceans. Mar. Biotechnol. 2006, 8, 203-226. [CrossRef] [PubMed]

38. Zargar, V.; Asghari, M.; Dashti, A. A review on chitin and chitosan polymers: Structure, chemistry, solubility, derivatives, and applications. ChemBioEng Rev. 2015, 2, 204-226. [CrossRef]

39. Tianwei, T.; Xiaojing, H.; Weixia, D. Adsorption behaviour of metal ions on imprinted chitosan resin. J. Chem. Technol. Biotechnol. 2001, 76, 191-195. [CrossRef]

40. Xu, L.; Huang, Y.; Zhu, Q.; Ye, C. Chitosan in molecularly-imprinted polymers: Current and future prospects. Int. J. Mol. Sci. 2015, 16, 18328-18347. [CrossRef]

41. Zouaoui, F.; Bourouina-Bacha, S.; Bourouina, M.; Jaffrezic-Renault, N.; Zine, N.; Errachid, A. Electrochemical sensors based on molecularly imprinted chitosan: A review. Trends Analyt. Chem. 2020, 130, 115982. [CrossRef]

42. Karrat, A.; Lamaoui, A.; Amine, A.; Palacios-Santander, J.M.; Cubillana-Aguilera, L. Applications of chitosan in molecularly and ion imprinted polymers. Chem. Afr. 2020, 3, 513-533. [CrossRef]

43. Di Bello, M.P.; Mergola, L.; Scorrano, S.; Del Sole, R. Towards a new strategy of a chitosan-based molecularly imprinted membrane for removal of 4-nitrophenol in real water samples. Polym. Int. 2017, 66, 1055-1063. [CrossRef]

44. Di Bello, M.P.; Lazzoi, M.R.; Mele, G.; Scorrano, S.; Mergola, L.; Del Sole, R. A new ion-imprinted chitosan-based membrane with an azo-derivative ligand for the efficient removal of Pd(II). Materials 2017, 10, 1133. [CrossRef] [PubMed]

45. Yu, Q.; Deng, S.; Yu, G. Selective removal of perfluorooctane sulfonate from aqueous solution using chitosan-based molecularly imprinted polymer adsorbents. Water Res. 2008, 3089-3097. [CrossRef] [PubMed]

46. Cheng, Y.; Xu, K.; Li, H.; Li, Y.; Liang, B. Preparation of urea-imprinted cross-linked chitosan and its adsorption behavior. Anal. Lett. 2014, 47, 1063-1078. [CrossRef]

47. Monier, M.; Abdel-Latif, D.A.; Abou El-Reash, J.G. Ion-imprinted modified chitosan resin for selective removal of Pd(II) ions. J. Colloid Interface Sci. 2016, 469, 344-354. [CrossRef]

48. Bagheri, A.R.; Arabi, M.; Ghaedi, M.; Ostovan, A.; Wang, X.; Li, J.; Chen, L. Dummy molecularly imprinted polymers based on a green synthesis strategy for magnetic solid-phase extraction of acrylamide in food samples. Talanta 2019, 195, 390-400. [CrossRef] [PubMed]

49. Bagheri, A.R.; Ghaedi, M. Green preparation of dual-template chitosan-based magnetic water-compatible molecularly imprinted biopolymer. Carbohydr. Polym. 2020, 236, 116102. [CrossRef] [PubMed]

50. Barati, A.; Kazemi, E.; Dadfarnia, S.; Haji Shabani, A.M. Synthesis/characterization of molecular imprinted polymer based on magnetic chitosan/graphene oxide for selective separation/preconcentration of fluoxetine from environmental and biological samples. J. Ind. Eng. Chem. 2017, 46, 212-221. [CrossRef]

51. Surya, S.G.; Khatoon, S.; Lahcen, A.A.; Nguyen, A.T.H.; Dzantiev, B.B.; Tarannum, N.; Salama, K.N. Chitosan gold nanoparticles molecularly imprinted polymer based ciprofloxacin sensor. RSC Adv. 2020, 10, 12823-12832. [CrossRef]

52. Wang, L.; Li, J.; Wange, J.; Guo, X.; Wang, X.; Choo, J.; Chen, L. Green multi-functional monomer based ion imprinted polymers for selective removal of copper ions from aqueous solution. J. Colloid Interface Sci. 2019, 541, 376-386. [CrossRef] [PubMed]

53. He, J.; Lu, Y.; Luo, G. Ca(II) imprinted chitosan microspheres: An effective and green adsorbent for the removal of Cu(II), Cd(II) and $\mathrm{Pb}$ (II) from aqueous solutions. Chem. Eng. J. 2014, 244, 202-208. [CrossRef] 
54. Zhu, Y.; Bai, Z.S.; Wang, H.L. Microfluidic synthesis of thiourea modified chitosan microsphere of high specific surface area for heavy metal wastewater treatment. Chin. Chem. Lett. 2017, 28, 633-641. [CrossRef]

55. Kuthi, F.A.B.A.; Badri, K.H. Effect of cooking temperature on the crystallinity of acid hydrolysed-oil palm cellulose. In AIP Conference Proceedings 1614; American Institute of Physics: College Park, MD, USA, 2014; Volume 456. [CrossRef]

56. Hu, Z.H.; Wang, Y.F.; Ahmed Mohamed Omer, A.M.; Ouyang, X.K. Fabrication of ofloxacin imprinted polymer on the surface of magnetic carboxylated cellulose nanocrystals for highly selective adsorption of fluoroquinolones from water. Int. J. Biol. Macromol. 2018, 107, 453-462. [CrossRef]

57. Brinchi, L.; Cotana, F.; Fortunati, E.; Kenny, J.M. Production of nanocrystalline cellulose from lignocellulosic biomass: Technology and applications. Carbohydr. Polym. 2013, 94, 154-169. [CrossRef] [PubMed]

58. Godage, N.H.; Gionfriddo, E. Use of natural sorbents as alternative and green extractive materials: A critical review. Anal. Chim. Acta 2020, 1125, 187-200. [CrossRef] [PubMed]

59. Nakai, Y.; Yoshikawa, M. Cellulose as a membrane material for optical resolution. Polym. J. 2015, 47, 334-339. [CrossRef]

60. Ullah, H.; Wahid, F.; Santos, H.A.; Khan, T. Advances in biomedical and pharmaceutical applications of functional bacterial cellulose-based nanocomposites. Carbohydr. Polym. 2016, 150, 330-352. [CrossRef]

61. Arca, H.C.; Mosquera-Giraldo, L.I.; Bi, V.; Xu, D.; Taylor, L.S.; Edgar, K.J. Pharmaceutical applications of cellulose ethers and cellulose ether esters. Biomacromolecules 2018, 19, 2351-2376. [CrossRef]

62. Sun, B.; Zhang, M.; Shen, J.; He, Z.; Fatehi, P.; Nik, Y. Application of cellulose-based materials in sustained drug delivery systems. Curr. Med. Chem. 2019, 26, 2485-2501. [CrossRef]

63. Andriani, D.; Apriyana, A.Y.; Karina, M. The optimization of bacterial cellulose production and its applications: A review. Cellulose 2020, 27, 6747-6766. [CrossRef]

64. Lou, Z.; Wen, S.; Wan, L.; Zhang, P.; Wang, Y.; Zhang, F.; Xiong, Y.; Fan, Y. High-performance waste cellulose based adsorbent used for determination of $\mathrm{Ag}(\mathrm{I})$ coordination anions. J. Polym. Environ. 2018, 26, 2650-2659. [CrossRef]

65. Shamsayei, M.; Yamini, Y.; Asiabi, H. Evaluation of highly efficient on-line yarn-in-tube solid phase extraction method for ultra-trace determination of chlorophenols in honey samples. J. Chromatogr. A 2018, 1569, 70-78. [CrossRef]

66. Liang, X.; Liu, S.; Zhu, R.; Xiao, L.; Yao, S. Highly sensitive analysis of polycyclic aromatic hydrocarbons in environmental water with porous cellulose/zeolitic imidazolate framework-8 composite microspheres as a novel adsorbent coupled with high-performance liquid chromatography. J. Sep. Sci. 2016, 39, 2806-2814. [CrossRef] [PubMed]

67. Abujaber, F.; Zougagh, M.; Jodeh, S.; Ríos, A.; Bernardo, F.J.G.; Doimeadios, R.R.M. Magnetic cellulose nanoparticles coated with ionic liquid as a new material for the simple and fast monitoring of emerging pollutants in waters by magnetic solid phase extraction. Microchem. J. 2018, 137, 490-495. [CrossRef]

68. Al-Maibd, R.; Al-Ashaq, W.; Zainuddin, N.; Ibrahim, N.A.; Samsudin, I.N.; Yahaya, N.; Kamaruzaman, S. Synthesis and optimization selective ion-imprinted polymer for the elimination of Ca II ions using Taguchi design. J. Polym. Res. 2021, 28, 84. [CrossRef]

69. Derazshamishir, A.; Göktürk, I.; Tamahkar, E.; Yılmaz, F.; Sağlam, N. Phenol removal from wastewater by surface imprinted bacterial cellulose nanofibers. Environ. Technol. 2020, 41, 3134-3145. [CrossRef] [PubMed]

70. Farenghi, A.R.; Moghadam, P.N.; Khalaf, J. Synthesis and characterization of a cellulose-based molecularly imprinted polymer in aqueous solution: The study of Furosemide slow release. Stärke 2017, 69, 1700002. [CrossRef]

71. Fattahi, M.; Ezzatzadeh, E.; Jalilian, R.; Taheri, A. Micro solid phase extraction of cadmium and lead on a new ion-imprinted hierarchical mesoporous polymer via dual-template method in river water and fish muscles: Optimization by experimental design. J. Hazard. Mater. 2021, 403, 123716. [CrossRef]

72. Jantarat, C.; Attakitmongkol, K.; Nichsapa, S.; Sirathanarun, P.; Srivaro, S. Molecularly imprinted bacterial cellulose for sustainedrelease delivery of quercetin. J. Biomater. Sci. Polym. Ed. 2020, 31, 1961-1976. [CrossRef] [PubMed]

73. Lin, C.; Qiu, Y.; Fan, J.; Wang, M.; Ye, L.; Liu, Y.; Ye, X.; Huang, X.; Lv, Y.; Liu, M. Fabrication of photo-responsive cellulose based intelligent imprinted material and selective adsorption on typical pesticide residue. Chem. Eng. J. 2020, 394, 124841. [CrossRef]

74. Piacham, T.; Isarankura-Na-Ayudhya, C.; Prachayasittikul, V. A simple method for creating molecularly imprinted polymercoated bacterial cellulose nanofibers. Chem. Pap. 2014, 68, 838-841. [CrossRef]

75. Sueyoshi, Y.; Fukushima, C.; Yoshikawa, C. Molecularly imprinted nanofiber membranes from cellulose acetate aimed for chiral separation. J. Membr. Sci. 2010, 357, 90-97. [CrossRef]

76. Tamahkar, E.; Bakhshpour, M.; Denizli, A. Molecularly imprinted composite bacterial cellulose nanofibers for antibiotic release. Biomater. Sci. Polym. Ed. 2019, 30, 450-461. [CrossRef] [PubMed]

77. Velempini, T.; Pillay, K.; Mbianda, X.Y.; Arotiba, O.A. Carboxymethyl cellulose thiol-imprinted polymers: Synthesis, characterization and selective $\mathrm{Hg}(\mathrm{II})$ adsorption. J. Environ. Sci. 2019, 79, 280-296. [CrossRef] [PubMed]

78. Velempini, T.; Pillay, K.; Mbianda, X.Y.; Arotiba, O.A. Application of a polypyrrole/carboxy methyl cellulose ion imprinted polymer in the electrochemical detection of mercury in water. Electroanalysis 2018, 30, 2612-2619. [CrossRef]

79. Wang, Y.F.; Wang, Y.G.; Ouyang, X.K. Surface-imprinted magnetic carboxylated cellulose nanocrystals for the highly selective extraction of six fluoroquinolones from egg samples. ACS Appl. Mater. Interfaces 2017, 9, 1759-1769. [CrossRef]

80. Wang, P.; Zhang, A.; Jin, Y.; Zhang, Q.; Zhang, L.; Peng, Y.; Du, S. Molecularly imprinted layer-coated hollow polysaccharide microcapsules toward gate-controlled release of water-soluble drugs. RSC Adv. 2014, 4, 26063. [CrossRef] 
81. Wu, Y.; Xing, W.; Yan, J.; Cui, J.; Ma, F.; Gao, J.; Lu, J.; Yu, C.; Yan, M. Multilevel mineral-coated imprinted nanocomposite membranes for template-dependent recognition and separation: A well-designed strategy with $\mathrm{PDA} / \mathrm{CaCO}_{3}$-based loading structure. J.Colloid Interface Sci. 2020, 575, 356-366. [CrossRef]

82. Wu, Y.; Lin, R.; Ma, F.; Xing, W.; Pan, J. Three-dimensional macroporous wood-based selective separation membranes decorated with well-designed $\mathrm{Nd}(\mathrm{III})$-imprinted domains: A high-efficiency recovery system for rare earth element. J. Colloid Interface Sci. 2021, 587, 703-714. [CrossRef]

83. Zheng, X.; Zhang, Y.; Bian, T.; Zhang, Y.; Li, Z.; Pan, J. Oxidized carbon materials cooperative construct ionic imprinted cellulose nanocrystals films for efficient adsorption of Dy(III). Chem. Eng. J. 2020, 381, 122669. [CrossRef]

84. Kenawy, I.M.; Ismail, M.A.; Hafez, M.A.H.; Hashem, M.A. Synthesis and characterization of novel ion-imprinted guanyl-modified cellulose for selective extraction of copper ions from geological and municipality sample. Int. J. Biol. Macromol. 2018, 115, 625-634. [CrossRef]

85. Wang, J.; Wei, J.; Li, J. Straw-supported ion imprinted polymer sorbent prepared by surface imprinting technique combined with AGET ATRP for selective adsorption of $\mathrm{La}^{3+}$ ions. Chem. Eng. J. 2016, 293, 24-33. [CrossRef]

86. Ioannidou, O.; Zabaniotou, A. Agricultural residues as precursors for activated carbon production-A review. Renew. Sustain. Energy Rev. 2007, 11, 1966-2005. [CrossRef]

87. Dias, J.M.; Alvim-Ferraz, M.C.M.; Almeida, M.F.; Rivera-Utrilla, J.; Sánchez-Polo, M. Waste materials for activated carbon preparation and its use in aqueous-phase treatment: A review. J. Environ. Manag. 2007, 85, 833-846. [CrossRef]

88. Danish, M.; Ahmad, T. A review on utilization of wood biomass as a sustainable precursor for activated carbon production and application. Renew. Sustain. Energy Rev. 2018, 87, 1-21. [CrossRef]

89. Abioye, A.M.; Ani, F.N. Recent development in the production of activated carbon electrodes from agricultural waste biomass for supercapacitors: A review. Renew. Sustain. Energy Rev. 2015, 52, 1282-1293. [CrossRef]

90. Tan, X.-F.; Liu, S.-B.; Liu, Y.-G.; Gu, Y.-L.-; Zeng, G.-M.; Hu, X.-J.; Wang, X.; Liu, S.-H.; Jiang, L.-H. Biochar a potential sustainable precursors for activated carbon production: Multiple applications in environmental protection and energy storage. Bioresour. Technol. 2017, 227, 359-372. [CrossRef]

91. Zhang, S.; Yang, X.; Liu, L.; Ju, M.; Zheng, K. Adsorption behavior of selective recognition functionalized biochar to Cd(II) in wastewater. Materials 2018, 11, 299. [CrossRef]

92. $\mathrm{Su}, \mathrm{W} . ;$ Wang, R.; Zhao, T. Co2-imprinted sustainable carbon derived from sunflower heads for highly effective capture of $\mathrm{CO}_{2}$ from flue gas. Aerosol Air Qual. Res. 2020, 20, 180-192. [CrossRef]

93. Saputra, N.A.; Pari, G.; Darmawan, S.; Hendra, D.; Harsini, M. Syntesis and property of porous material for sustainable resources-based biosensor: A review. IOP Conf. Ser. Mater. Sci. Eng. 2020, 980, 012029. [CrossRef]

94. Ding, Q.; Guo, Z.; Chen, W.; Yu, H.; Zhu, X.; Liu, Q.; Fu, M. Biomass activated carbon-derived imprinted polymer with multi-boronic acid sites for selective capture of glycoprotein. J. Colloid Interface Sci. 2021, 596, 225-232. [CrossRef]

95. Sun, X.; Lei, Y. Fluorescent carbon dots and their sensing applications. Trends Anal. Chem. 2017, 89, 163-180. [CrossRef]

96. Xu, X.Y.; Ray, R.; Gu, Y.L.; Ploehn, H.J.; Gearheart, L.; Raker, K.; Scrivens, W.A. Electrophoretic analysis and purification of fluorescent single-walled carbon nanotube fragments. J. Am. Chem. Soc. 2004, 126, 12736-12737. [CrossRef]

97. Sun, Y.P.; Bing, Z.; Yi, L.; Wei, W.; Fernando, K.A.S.; Pathak, P.; Meziani, M.J.; Harru, B.A.; Xin, W.; Wang, H. Quantum-sized carbon dots for bright and colorful photoluminescence. J. Am. Chem. Soc. 2006, 128, 7756-7757. [CrossRef] [PubMed]

98. Yang, T.; Huang, J.L.; Wang, Y.T.; Zheng, A.Q.; Shu, Y.; Wang, J.H. $\beta$-cyclodextrin-decorated carbon dots serve as nanocarriers for targeted drug delivery and controlled release. ChemNanoMat 2019, 5, 479-487. [CrossRef]

99. Yu, H.J.; Shi, R.; Zhao, Y.F.; Waterhouse, J.I.N.; Wu, L.Z.; Tung, C.H.; Zhang, T.R. Smart utilization of carbon dots in semiconductor photocatalysis. Adv. Mater. 2016, 28, 9454-9477. [CrossRef] [PubMed]

100. Zheng, J.X.; Liu, X.H.; Yang, Y.Z.; Liu, X.G.; Xu, B.S. Rapid and green synthesis of fluorescent carbon dots from starch for white light-emitting diodes. New Carbon Mater. 2018, 33, 276-288. [CrossRef]

101. Hu, C.; Li, M.Y.; Qiu, J.S.; Sun, Y.P. Design and fabrication of carbon dots for energy conversion and storage. Chem. Soc. Rev. 2019, 48, 2315-2337. [CrossRef]

102. Cheng, C.; Shi, Y.; Li, M.; Xing, M.; Wu, Q. Carbon quantum dots from carbonized walnut shells: Structural evolution, fluorescence characteristics, and intracellular bioimaging. Mater. Sci. Eng. C 2017, 79, 473-480. [CrossRef]

103. Pandey, H.; Khare, P.; Singh, S.; Singh, S.P. Carbon nanomaterials integrated molecularly imprinted polymers for biological sample analysis: A critical review. Mater. Chem. Phys. 2020, 239, 121966. [CrossRef]

104. Xiao, D.; Su, L.; Teng, Y.; Hao, J.; Bi, Y. Fluorescent nanomaterials combined with molecular imprinting polymer: Synthesis, analytical applications, and challenges. Microchim. Acta 2020, 187, 399. [CrossRef]

105. Liu, H.; Ding, L.; Chen, L.; Chen, Y.; Zhou, T.; Li, H.; Xu, Y.; Zhao, L.; Huang, N. A facile, green synthesis of biomass carbon dots coupled with molecularly imprinted polymers for highly selective detection of oxytetracycline. J. Ind. Eng. Chem. 2019, 69, 455-463. [CrossRef]

106. Shariati, R.; Rezaei, B.; Jamei, H.R.; Ensafi, A.A. Application of coated green source carbon dots with silica molecularly imprinted polymers as a fluorescence probe for selective and sensitive determination of phenobarbital. Talanta 2019, 194, 143-149. [CrossRef]

107. Liu, H.; Ding, J.; Zhang, K.; Ding, L. Fabrication of carbon dots@restricted access molecularly imprinted polymers for selective detection of metronidazole in serum. Talanta 2020, 209, 120508. [CrossRef] [PubMed] 
108. Sun, X.; Liu, Y.; Niu, N.; Chen, L. Synthesis of molecularly imprinted fluorescent probe based on biomass-derived carbon quantum dots for detection of mesotrione. Anal. Bioanal. Chem. 2019, 411, 5519-5530. [CrossRef] [PubMed]

109. Kazemifard, N.; Ensafi, A.A.; Rezaei, B. Green synthesized carbon dots embedded in silica molecularly imprinted polymers, characterization and application as a rapid and selective fluorimetric sensor for determination of thiabendazole in juices. Food Chem. 2020, 310, 125812. [CrossRef]

110. Demir, B.; Lemberger, M.M.; Panagiotopoulou, M.; Medina Rangel, P.X.; Timur, S.; Hirsch, T.; Tse Sum Bui, B.; Wegener, J.; Haupt, K. Tracking hyaluronan: Molecularly imprinted polymer coated carbon dots for cancer cell targeting and imaging. ACS Appl. Mater. Interfaces 2018, 10, 3305-3313. [CrossRef] [PubMed]

111. Rajput, K.N.; Patel, K.C.; Trivedi, U.B. $\beta$-cyclodextrin production by cyclodextrin glucanotransferase from an alkaliphile microbacterium terrae KNR 9 using different starch substrates. Biotechnol. Res. Int. 2016, 2016, 1-7. [CrossRef]

112. Gentili, A. Cyclodextrin-based sorbents for solid phase extraction. J. Chromatogr. A 2020, 1609, 460654. [CrossRef]

113. Szejtli, J. Past, present, and future of cyclodextrin research. Pure Appl. Chem. 2004, 76, 1825-1845. [CrossRef]

114. Bruns, C.J. Exploring and exploiting the symmetry-breaking effect of cyclodextrins in mechanomolecules. Symmetry 2019, 11, 1249. [CrossRef]

115. Lay, S.; Ni, X.; Yu, H.; Shen, S. State-of-the-art applications of cyclodextrins as functional monomers in molecular imprinting techniques: A review. J. Sep. Sci. 2016, 39, 2321-2331. [CrossRef] [PubMed]

116. He, Y.; Zeng, S.; Abd El-Aty, A.M.; Hacımüftüǒglu, A.; Yohannes, W.K.; Khan, M.; She, Y. Development of water-compatible molecularly imprinted polymers based on functionalized $\beta$-cyclodextrin for controlled release of atropine. Polymers 2020, 12, 130. [CrossRef] [PubMed]

117. Mamman, S.; Suah, F.B.M.; Raaov, M.; Mehamod, F.S.; Asman, S.; Zain, N.N.M. Removal of bisphenol A from aqueous media using a highly selective adsorbent of hybridization cyclodextrin with magnetic molecularly imprinted polymer. R. Soc. Open Sci. 2021, 8, 201604. [CrossRef] [PubMed]

118. Zhao, X.; Wang, Y.; Zhang, P.; Lu, Z.; Xiao, Y. Recent advances of molecularly imprinted polymers based on cyclodextrin. Macromol. Rapid Commun. 2021, 42, 2100004. [CrossRef]

119. Feng, G.; Ping, W.; Qin, X.X.; Liu, J.; Zhu, X. Ionic-liquid-loaded $\beta$-cyclodextrin-cross-linked polymer solid-phase extraction for the separation/analysis of linuron in fruit and vegetable samples. Food Anal. Methods 2015, 8, 2315-2320. [CrossRef]

120. Farooq, S.; Nie, J.; Cheng, Y.; Bacha, S.A.S.; Chang, W. Selective extraction of fungicide carbendazim in fruits using $\beta$-cyclodextrin based molecularly imprinted polymers. J. Sep. Sci. 2020, 43, 1145-1153. [CrossRef]

121. Chen, M.; Dong, Q.; Ni, W.; Zhao, X.; Gu, Q.; Tang, G.; Li, D.; Ma, W.; Hou, Z. Cyclodextrin-based polymer-assisted Ru nanoparticles for the aqueous hydrogenation of biomass-derived platform molecules. Chem. Select. 2017, 2, 10537-10545. [CrossRef]

122. Dolai, J.; Ali, H.; Jana, N.R. Molecular imprinted poly-cyclodextrin for selective removal of dibutyl phthalate. ACS Appl. Polym. Mater. 2020, 2, 691-698. [CrossRef]

123. Ma, J.-K.; Huang, X.-C.; Wei, S.-L. Preparation and application of chlorpyrifos molecularly imprinted solid-phase microextraction probes for the residual determination of organophosphorous pesticides in fresh and dry foods. J. Sep. Sci. 2018, 41, 3152-3162. [CrossRef]

124. Guo, H.; Xiong, J.; Ma, W.; Wu, M.; Yan, L.; Li, K.; Liu, Y. Synthesis of molecularly imprinted polymers using acrylamidecyclodextrin as a cofunctional monomer for the specific capture of tea saponins from the defatted cake extract of Camellia oleifera. J. Sep. Sci. 2016, 39, 4439-4448. [CrossRef]

125. Tang, W.; Du, W.; Guo, P.; Wu, N.; Du, K.; Xu, C.; Luo, Z.; Chang, R.; Zeng, A.; Jing, W.; et al. Molecularly imprinted solid phase extraction using bismethacryloyl- $\beta$-cyclodextrin and methacrylic acid as double functional monomers for selective analysis of glycyrrhizic acid in aqueous media. J. Chromatogr. Sci. 2017, 55, 166-173. [CrossRef] [PubMed]

126. Tan, L.; Li, Y.; Deng, F.; Pan, X.; Yu, H.; Marina, M.L.; Jiang, Z. Highly sensitive determination of amanita toxins in biological samples using $\beta$-cyclodextrin collaborated molecularly imprinted polymers coupled with ultra-high performance liquid chromatography tandem mass spectrometry. J. Chromatogr. A 2020, 1630, 461514. [CrossRef]

127. Wang, C.; Cheng, L.; Zhang, L.; Zuo, Y. Graphene oxide based molecularly imprinted polymers modified with $\beta$-cyclodextrin for selective extraction of di(2-ethylhexyl) phthalate in environmental waters. J. Sep. Sci. 2019, 42, 1248-1256. [CrossRef] [PubMed]

128. Sedghi, R.; Heidari, B.; Yassari, M. Novel molecularly imprinted polymer based on $\beta$-cyclodextrin@graphene oxide: Synthesis and application for selective diphenylamine determination. J. Colloid Interface Sci. 2017, 503, 47-56. [CrossRef] [PubMed]

129. Zhu, F.; Li, L.; Xing, J. Selective adsorption behavior of Cd(II) ion imprinted polymers synthesized by microwave-assisted inverse emulsion polymerization: Adsorption performance and mechanism. J. Hazard. Mater. 2017, 321, 103-110. [CrossRef]

130. Yu, T.; Xue, Z.; Zhao, X.; Chen, W.; Mu, T. Green synthesis of porous $\beta$-cyclodextrin polymers for rapid and efficient removal of organic pollutants and heavy metal ions from water. New J. Chem. 2018, 42, 16154-16161. [CrossRef]

131. Liang, G.; Guo, X.; Tan, X.; Mai, S.; Chen, Z.; Zhai, H. Molecularly imprinted monolithic column based on functionalized $\beta$ cyclodextrin and multi-walled carbon nanotubes for selective recognition of benzimidazole residues in citrus samples. Microchem. J. 2019, 146, 1285. [CrossRef]

132. Xu, Z.; Deng, P.; Li, J.; Xu, L.; Tang, S.; Zhang, F. Construction of imprint sites in mesopores of SBA-15 via thiol-ene click reaction. J. Mater. Sci. 2016, 51, 6295-6308. [CrossRef] 
133. Zhang, Y.; Li, J.; Wang, F.; Wu, G.; Qv, X.; Hong, H.; Liu, C. Recovery and separation of erythromycin from industrial wastewater by imprinted magnetic nanoparticles that exploit $\beta$-cyclodextrin as the functional monomer. J. Sep. Sci. 2016, 39, 450-459. [CrossRef]

134. Shi, J.; Li, G.; Cui, Y.; Zhang, Y.; Liu, D.; Shi, Y.; He, H. Surface-imprinted $\beta$-cyclodextrin-functionalized carbon nitride nanosheets for fluorometric determination of sterigmatomycin. Microchim. Acta 2019, 186, 808-817. [CrossRef]

135. Gao, J.W.; Xiong, H.W.; Zhang, W.; Wang, Y.; Wang, H.X.; Wen, W.; Zhang, X.H.; Wang, S.F. Electrochemiluminescent aptasensor based on beta-cyclodextrin/graphitic carbon nitride composite for highly selective and ultrasensitive assay of platelet derived growth factor BB. Carbon 2018, 130, 416-423. [CrossRef]

136. Sardaremelli, S.; Hasanzadeh, M.; Razmi, H. Chemical binding of horseradish peroxidase enzyme with poly beta-cyclodextrin and its application as molecularly imprinted polymer for the monitoring of $\mathrm{H}_{2} \mathrm{O}_{2}$ in human plasma samples. J. Mol. Recognit. 2021, 34, e2884. [CrossRef] [PubMed]

137. Tarannum, N.; Divya; Gautam, Y.K. Facile green synthesis and applications of sylver nanoparticles: A state-of-the-art review. RSC Adv. 2019, 9, 34926-34948. [CrossRef]

138. Sharma, D.; Kanchi, S.; Bisetty, K. Biogenic synthesis of nanoparticles: A review. Arab. J. Chem. 2019, 12, 3576-3600. [CrossRef]

139. Krishnaswamy, K.; Vali, H.; Orsat, V. Value-adding to grape waste: Green synthesis of gold nanoparticles. J. Food Eng. 2014, 142, 210-220. [CrossRef]

140. Balalakshmi, C.; Gopinath, K.; Govindarajan, M.; Lokesh, R.; Arumugam, A.; Alharbi, N.S.; Kadaikunnan, S.; Khaled, J.M.; Benellif, G. Green synthesis of gold nanoparticles using a cheap Sphaeranthus indicus extract: Impact on plant cells and the aquatic crustacean Artemia nauplii. J. Photochem. Photobiol. B 2017, 173, 598-605. [CrossRef]

141. Kaur, M.; Chopra, D. Green Synthesis of Iron Nanoparticles for Biomedical Applications. Glob. J. Nanomed. 2018, 4, 68-77.

142. Skiba, M.; Vorobyova, V.; Pivovarov, O.; Shakun, A.; Gnatko, E.; Trus, I. Green synthesis of nanoparticles of precious metals: Antimicrobial and catalytic properties. East. Eur. J. Enterp. Technol. 2018, 5, 51-58. [CrossRef]

143. Bastos-Arrieta, J.; Antonio Florido, A.; Pérez-Ràfols, C.; Serrano, N.; Fiol, N.; Poch, J.; Villaescusa, I. Green synthesis of Ag nanoparticles using grape stalk waste extract for the modification of screen-printed electrodes. Nanomaterials 2018, 8, 946. [CrossRef] [PubMed]

144. Zia, M.; Gul, S.; Akhtar, J.; ul Haq, I.; Abbasi, B.H.; Hussain, A.; Naz, S.; Chaudhary, M.F. Green synthesis of silver nanoparticles from grape and tomato juices and evaluation of biological activities. IET Nanobiotechnol. 2017, 11, 193-199. [CrossRef] [PubMed]

145. Kuppusamy, P.; Yusoff, M.M.; Maniam, G.P.; Govindan, N. Biosynthesis of metallic nanoparticles using plant derivatives and their new avenues in pharmacological applications-An updated report. Saudi. Pharm. J. 2016, 24, 473-484.

146. Mittal, A.K.; Chisti, Y.; Banerjee, U.C. Synthesis of metallic nanoparticles using plant extracts. Biotechnol. Adv. 2013, 31, 346-356. [CrossRef]

147. Hu, R.; Tang, R.; Xu, J.; Lu, F. Chemical nanosensors based on molecularly-imprinted polymers doped with silver nanoparticles for the rapid detection of caffeine in wastewater. Anal. Chim. Acta 2018, 1034, 176-183. [CrossRef]

148. Yin, W.; Wu, L.; Ding, F.; Li, Q.; Wang, P.; Li, J.; Lu, Z.; Han, H. Surface-imprinted SiO2@Ag nanoparticles for the selective detection of BPA using surface enhanced Raman scattering. Sens. Actuators B 2018, 258, 566-573. [CrossRef]

149. Matsui, J.; Akamatsu, K.; Nishiguchi, S.; Miyoshi, D.; Nawafune, H.; Tamaki, K.; Sugimoto, N. Composite of Au nanoparticles and molecularly imprinted polymer as a sensing material. Anal. Chem. 2004, 76, 1310-1315. [CrossRef]

150. López, A.S.; Ramos, M.P.; Herrero, R.; Vilariño, J.M.L. Synthesis of magnetic green nanoparticle-Molecular imprinted polymers with emerging contaminants templates. J. Environ. Chem. Eng. 2020, 8, 103889. [CrossRef]

151. Patra, S.; Ekta Roy, E.; Madhuri, R.; Sharma, P.K. Nanocomposite of bimetallic nanodendrite and reduced graphene oxide as a novel platform for molecular imprinting technology. Anal. Chim. Acta 2016, 918, 77-88. [CrossRef] [PubMed]

152. Essawy, A.A. Silver imprinted zinc oxide nanoparticles: Green synthetic approach, characterization and efficient sunlight-induced photocatalytic water detoxification. J. Clean. Prod. 2018, 183, 1011-1020. [CrossRef]

153. Le Goff, N.; Fomba, I.; Prost, E.; Merlier, F.; Haupt, K.; Duma, L.; Fayeulle, A.; Falcimaigne-Cordin, A. Renewable plant oil-based molecularly imprinted polymers as biopesticide delivery systems. ACS Sustain. Chem. Eng. 2020, 8, 15927-15935. [CrossRef]

154. Khurana, L.; Balasubramanian, K. Adsorption potency of imprinted Starch/PVA polymers confined ionic liquid with molecular simulation framework. J. Environ. Chem. Eng. 2016, 4, 2147-2154. [CrossRef] 